This is the accepted manuscript of the article, which has been published in Developmental Science. 2019, 22(5), e12761. https://doi.org/10.1111/desc.12761

\title{
Early development of visual attention in infants in rural Malawi
}

Juha Pyykkö (ORCiD: 0000-0001-6120-5323), Linda Forssman² (ORCiD: 0000-0003-02084212), Kenneth Maleta ${ }^{3}$ (ORCiD: 0000-0002-2536-3938), Per Ashorn ${ }^{1,4}$ (ORCiD: 00000003-2311-2593), Ulla Ashorn ${ }^{1}$ (ORCiD: 0000-0002-1720-868X), \& Jukka M. Leppänen (ORCiD: 0000-0003-3303-3602) $)^{1}$

${ }^{1}$ Tampere Center for Child Health Research, Faculty of Medicine and Life Sciences, University of Tampere, Tampere, Finland.

${ }^{2}$ Department of Psychology, Uppsala University, Uppsala, Sweden.

${ }^{3}$ Department of Public Health, School of Public Health and Family Medicine, College of Medicine, University of Malawi, Blantyre, Malawi.

${ }^{4}$ Department of Paediatrics, Tampere University Hospital, Tampere, Finland.

Corresponding Author: Juha Pyykkö

Postal address: University of Tampere, ARVO D538, 33014 University of Tampere, Finland Email: juha.pyykko@uta.fi 
Acknowledgments: We thank the participating families and the data collection team. This publication is based on research funded by the generous support of the American people through the support of the Office of Health, Infectious Diseases, and Nutrition, Bureau for Global Health, US Agency for International Development (USAID), under terms of Cooperative Agreement No. AIDOAA-A-12-00005, through the Food and Nutrition Technical Assistance III Project (FANTA), managed by FHI 360. Additional funding was provided by Tampere University Hospital (grant 9R001), Nutriset S.A.S, Tampere Association of Medical Doctors, Academy of Finland (\#2501271617), and the European Research Council (\#283763). JML, LF, KM, PA, and UA conceived and designed the study. LF trained data collectors. JML, KM, PA, UA, and JP assisted in data acquisition. JP and JML analyzed and interpreted data and wrote the first draft of the paper. All authors edited, reviewed and approved the final version of the article. 


\section{Research Highlights}

- Studies in infants in Western countries have shown that elementary attentional capabilities (orienting, anticipation, and prioritized processing of faces) emerge gradually during the first year.

- This study used automated eye tracking techniques to demonstrate similar attentional capabilities in a large sample of infants from rural Malawi.

- Compared to previous studies in Western populations, infants in Malawi exhibited selectively enhanced attentional bias for happy and fearful faces.

- Individual variations in infants' attentional capacities were moderately stable across tests, but not related to common risk factors (pre-term birth, poor nutritional status, psychosocial stress). 


\begin{abstract}
Eye tracking research has shown that infants develop a repertoire of attentional capacities during the first year. The majority of studies examining the early development of attention comes from Western, high-resource countries. We examined visual attention in a heterogeneous sample of infants in rural Malawi ( $N=312-376$, depending on analysis). Infants were assessed with eye-tracking-based tests that targeted visual orienting, anticipatory looking, and attention to faces at 7 and 9 months. Consistent with prior research, infants exhibited active visual search for salient visual targets, anticipatory saccades to predictable events, and a robust attentional bias for happy and fearful faces. Individual variations in these processes had low to moderate odd-even split-half and test-retest reliability. There were no consistent associations between attention measures and gestational age, nutritional status, or characteristics of the rearing environment (i.e., maternal cognition, psychosocial well-being, socioeconomic status, and care practices). The results replicate infants’ early attentional biases in a large, unique sample, and suggest that some of these biases (e.g., bias for faces) are pronounced in low-resource settings. The results provided no evidence that the initial manifestation of infants' attentional capacities is associated with risk factors that are common in low-resource environments.
\end{abstract}

Keywords: eye tracking, early development, visual attention, face perception, gestational age, low-resource 
Early development of visual attention in infants in rural Malawi

Basic attentional processes involved in attention orienting and holding, as well as prioritized processing of salient stimuli (e.g., faces) emerge gradually during the first year of life in infants (Amso, Haas, \& Markant, 2014; Gluckman \& Johnson, 2013; Hunnius, Geuze, \& Geert, 2006; Kulke, Atkinson, \& Braddick, 2015; Matsuzawa \& Shimojo, 1997; Valenza et al., 2015). These early-emerging capacities provide a basis for the acquisition of more complex visual, cognitive, and behavioral skills. Efficient orienting to visual stimuli - be it reactive or anticipatory - directs sharp foveal vision to most salient aspects of a visual scene, such as areas with highest contrast in color, intensity, orientation, or movement, or objects with social significance (Itti \& Koch, 2001; Weaver \& Lauwereyns, 2011). Similarly, the ability to localize and attend to a face and isolate it from the background is a prerequisite for subsequent "measurement" of the distinguishing characteristics of the face, as well as identification of an individual's identity, facial expression, and attentional focus (Frank, Vul, \& Johnson, 2009; Leppänen, 2016; Tsao, Schweers, Moeller, \& Freiwald, 2008).

Identification of these attributes may, in turn, help in initiating and maintaining social processes, eye contact, and dyadic interactions between the child and the caregiver (Klin, Shultz, \& Jones, 2015; see also Bedford, Pickles, Sharp, Wright, \& Hill, 2015; Peltola, Forssman, Puura, IJzendoorn, \& Leppänen, 2015).

While research on infant attention has increased in volume and improved in methods (e.g., by the advent of automated gaze tracking technologies), the majority of studies utilizing the advanced technologies of the field has been conducted in Europe, North America and Japan (Forssman et al., 2017). This “sampling bias” reflects a wider problem in developmental sciences as an overwhelming majority of developmental research relies on participant from “Western, educated, industrialized, rich, and demographic” settings and, as 
such is under-representative of the global population as a whole (Nielsen, Haun, Kärtner, \& Legare, 2017).

Expanding the studies of infants' early development to new populations would not only improve the representativeness of the field's participant pool (Nielsen et al., 2017), but also help to understand how the allegedly fundamental aspects of human cognition emerge in heterogeneous rearing environments. Infants born in low-resource settings in developing countries lack access to resources that are considered "standard” for an optimal rearing environment, such as consistent nutrition and sufficient levels of social and cognitive stimulation (Walker et al., 2011). Studying how basic neurocognitive processes emerge in these contexts may help to identify patterns that are shared by infants across very different environments, and potentially also on characteristics that reflect more culturally specific adaptations and may have a role in longer term developmental outcomes of children in these environments. For example, it is not known whether deviations in early development of basic neurocognitive processes (e.g., visual attention) play a role in the long-term cognitive deficits in children who have been experienced early life malnutrition and other covarying risk factors (Sudfeld et al., 2015).

In the current study, we examined the early development of visual attentional capacities in a sample of infants in rural Malawi. We focused on three attentional capacities that are well-documented in infants during the second half of the first year: visual search for a target in the presence of various number and types of interfering stimuli (Frank et al., 2009; Kaldy, Kraper, Carter, \& Blaser, 2011), anticipatory attention shifts (Kovács \& Mehler, 2009), and prioritized allocation of attention to faces (e.g., Amso et al., 2014; Gluckman \& Johnson, 2013; Leppänen, 2016).

Based on the results of a previous small-scale study with Malawian infants (Forssman et al., 2017), we expected that similar to infants in high-resource settings, Malawian infants 
search for salient targets in the presence of distracting stimuli, exhibit anticipatory eye movements to predictable visual stimuli, update these anticipatory responses after a change in stimulus contingency, and show differential attention to non-face stimuli and faces, as well as happy compared to fearful facial expressions. Aside from assessing infant attention capacities at group level, we assessed individual differences in these behaviors, and the reproducibility of these differences over time. The reproducibility of individual variations is affected by instrumental reliability, which can be assessed by odd-even split-half correlations (Klein \& Fischer, 2005), and by the stability of the behavior itself. Previous studies in infants in highresource settings have shown that the odd-even split-half correlations can vary significantly for different measures of infant attention (.38 to .88, Ahtola et al., 2014; Gillespie-Smith et al., 2016; Rose, Feldman, \& Jankowski, 2012). The test-retest correlations for measures similar to those used in the current study have ranged from .53 to .76 over a one-week or twoweek interval (Cousijn, Hessels, Van der Stigchel, \& Kemner, 2017; Leppänen, Forssman, Kaatiala, Yrttiaho, \& Wass, 2015; Rose et al., 2012) and from .40 to .76 over a two-month interval (Leppänen et al., 2015; Yrttiaho, Forssman, Kaatiala, \& Leppänen, 2014).

In addition to the reproducibility of individual differences, we examined whether these differences were associated with risk factors that are common in low-resource settings, particularly preterm birth, but also malnutrition and psychosocial risk factors. The possibility that infants early attentional behaviors are sensitive to these risk factors is suggested by previous studies in high-resource settings showing slower visual orientation (Landry, Leslie, Fletcher, \& Francis, 1985; Pel et al., 2016; Shah et al., 2006; however, see also Foreman, Fielder, Price, \& Bowler, 1991; Hunnius, Geuze, Zweens, \& Bos, 2008; Rose, Feldman, Jankowski, \& Caro, 2002 for contrary evidence), slower attention shifts between two competing objects (Butcher, Kalverboer, Geuze, \& Stremmelaar, 2002; de Jong, Verhoeven, \& van Baar, 2015; Atkinson et al., 2008), and reduced attention to faces (Telford et al., 2016) 
in preterm infants. Further, various sources of evidence from high- and low-resource settings point to poorer cognitive function in growth-stunted children (Champakam, Srikantia, \& Gopalan, 1968; Galler et al., 2013; Rose, 1994; Thompson et al., 2015) and in children raised in low socioeconomic status households (Hackman, Gallop, Evans, \& Farah, 2015). Finally, two recent studies suggest that infants’ age-typical attentional biases (i.e., heightened attention to threat-alerting faces) are exacerbated in response to early life psychosocial stress (Forssman et al., 2014; Morales et al., 2017).

\section{Methods}

\section{Design and Participants}

The current analyses use data from a prospective cohort study of infants born in Lungwena and Malindi areas, Mangochi District, Malawi. Newborn infants who were born between 32.0 and 41.9 gestation weeks (gw), and had no known congenital malformation, severe illness that prevented participation as judged clinically by the study nurse, or visual impairment were enrolled in the study.

Prior to the enrollment, a study nurse performed an obstetric ultrasound assessment of all women who started antenatal care at Lungwena or Malindi Health facilities. The nurse measured fetal biparietal diameter, femur length, and abdominal circumference and determined the duration of pregnancy based on these measurements and Hadlock tables. The results and the estimated date of delivery were recorded in a logbook and the woman's health passport, so that the information could later be retrieved to calculate gestational age at birth (GA) for those individuals who were later enrolled in the prospective cohort study. The enrollment took place after the child's birth, before the child was 28-days-old.

Recruitment for the prospective cohort study was stratified based on infants’ GA to enroll 425 infants born between 32.0 and 36.9 completed gw (preterm), between 37.0 and 38.9 gw (early term), and between 39.0 and 41.9 gw (full term) at a ratio of 1:2:2. These 
categories were selected based on a recent redefinition of a term pregnancy (ACOG, 2013). The ratio of enrollment was changed to 1:5:5 after 251 participants had been enrolled due to a slower-than-expected recruitment pace for preterm infants.

The current analyses are based on post-enrollment clinic visits conducted at the Lungwena health center at the chronological age of 7 and 9 months (30 and 39 weeks after birth, \pm 14 days, respectively), when eye tracking measures were taken. Also, the current analyses included data on the child's weight, length, mid-upper-arm circumference, and head circumference, taken at the enrollment and 7- and 9-month clinic visits, as well as parent questionnaire data collected at different post-enrollment visits (Table S1).

We conducted the study in accordance with the ethical standards of the Helsinki declaration. The study protocol was approved by the College of Medicine Research and Ethics Committee, Malawi; the Ethics Committee of Pirkanmaa Hospital District, Finland; and the Ethics Committee of the Tampere Region, Finland. Mothers signed or thumb printed the consent form, on behalf of themselves and their infants.

\section{Eye Tracking Assessment}

Setting and equipment. Infants were assessed in an air-conditioned room, within a 2 x $2 \mathrm{~m}$ partition that was separated from the other parts of the room by black fabric. Infants were seated on their mother's lap in a baby carrier so that the infant's eyes were at approximately $60 \mathrm{~cm}$ viewing distance from a 22-inch widescreen monitor (Dell Inc., TX) with a Tobii X2-60 eye tracker (Tobii Technology, Stockholm, Sweden). The light sources inside the partition were the monitor and an E14 LED light bulb placed about 2 meters from the floor (slightly behind the participant).

A script for stimulus presentation was written on MATLAB (Mathworks, Natick, MA), and ran on MacBook Pro OS X 10.9 (Apple Inc., CA) computer. Stimulus presentation software and hardware interfaced via Psychtoolbox and Tobii SDK plug-in. Eye tracking data 
were initially saved as MATLAB .mat-files and subsequently converted into the Tobii .gazedata-format.

Two Malawian experimenters performed the eye tracking assessments. The experimenters sat behind a curtain out of the infant's view during the testing session. The experimenters monitored the infant's behavior through a video feed as well as a real-time visualization of infant gaze position. If the infant became restless, inattentive, or fussy during the assessment, a break was taken. If the eye tracking system lost tracking of the infants' eyes or tracking became flickery, the experimenter paused the task and adjusted infant's position.

Procedure. Infants viewed a sequence of visual stimuli to calibrate the eye tracking camera, and to assess infants’ i) visual search, ii) anticipatory attention shifts, and iii) attention to faces. The tasks were performed twice for each infant in two separate sessions, with a break in between the sessions. (The child took part in a separate, structural observation assessment during the break in another research room. Data from the structural observation assessment will be reported separately.)

Calibration. During the calibration, five cartoon figures $\left(4^{\circ}\right)$ with accompanying sounds appeared, one at a time, in each corner and in the center of the screen. The outcome of the calibration was evaluated by the experimenter based on visual inspection of the calibrated data points for the two eyes, and comparison of the calibration outcome with predefined standard for acceptable calibration. Any unsuccessful calibration was recalibrated once or twice to reach satisfactory calibration. If one or more calibration points were missing after two attempts to recalibrate, the calibration was accepted, and the experiment was started.

Visual search. This task (modeled on Kaldy et al., 2011) started with the presentation of an oh sound and an image of a red apple ( $5^{\circ}$ visual angle) on the center of the screen. After the infant had fixated the stimulus and 2000 ms had elapsed (or a maximum wait period of $4000 \mathrm{~ms}$ had elapsed), a blank screen was presented for $500 \mathrm{~ms}$, followed by 
the re-appearance of the apple in a randomly chosen location on the screen. Depending on an experimental condition, the apple was presented alone (one-object condition) or among four or eight distractors of one kind (multiple-objects condition), or among distractors of two kinds (conjunction condition) (Figure 1). The distractors were either blue apples (same shape, but different color) or rectangle-shaped sliced apples (same color, but different shape). In the conjunction trials, half of the distractor objects were blue apples and the other half red sliced apples. If the participant fixated the target within $4 \mathrm{~s}$ from the start of the trial, a reward sound (children voices cheering yeah) was played while the target spun. The same audiovisual effect was presented to the participant if s/he didn’t find the target within $4 \mathrm{~s}$ to make the task more engaging and to draw attention to the target. Successful search was registered if the gaze hit the area of interest (a red apple) within a predefined time limit (150-2000 ms). There was a total of eight trials per condition in two sessions.

Anticipatory attention shifts. A task that was originally used by Kovács and Mehler (2009) was adapted to examine infant's ability to use an auditory cue to anticipate the appearance of a visual stimulus (i.e., an auditory cue followed after a constant interval with the presentation of a cartoon animation on the same location on the screen), and subsequently change this response as the cue-stimulus contingency was changed (i.e., when the cue remained the same but the visual stimulus was presented on a new location on the screen). At the start of each trial in this task, infants were presented with a fixation stimulus (a pink pig face, $5^{\circ}$ visual angle) in the center of the screen. After the infant looked at the fixation stimulus, an auditory cue and two visual placeholders (empty rectangles) were presented to the left and right side of the screen so that the furthest edge of the rectangles bordered the edge of the screen $\left(22^{\circ}\right.$ away from the center). If the infant made a "correct" anticipatory saccade to the placeholder where a salient visual stimulus was to be presented, or after 1000 ms had passed, an audiovisual reward appeared for 2000 ms within the rectangle. The reward 
appeared on one and the same side (left or right) during the first eight trials (pre-switch) and then, the side was switched so that the reward was presented on the other side on the last eight trials (post-switch). There was a total of 16 pre-switch and 16 post-switch trials in two sessions.

Attention to faces. A two-stimulus competition paradigm that has been previously used in Western countries was used to assess infants' attention to non-face control stimuli and faces. Following the descriptions of this task in previous studies (Ahtola et al., 2014; Leppänen et al., 2011; Leppänen, 2016; Peltola, Leppänen, Palokangas, \& Hietanen, 2008; Peltola, Hietanen, Forssman, \& Leppänen, 2013), each trial started with a dynamic attentiongrabbing stimulus presented on the center of the screen. After the infant fixated on the stimulus (i.e., infant point of gaze entered a predefined area of interest in the center of the screen), two stimuli were presented with a 1000 ms onset asynchrony. The first was presented on the center of the screen and the second laterally on the left or right side of the screen. The furthest edge of lateral stimulus bordered the edge of the screen $\left(22^{\circ}\right.$ away from the center). The first stimulus was a picture of a non-face pattern or a face displaying a happy or fearful expression. The non-face-patterns were created by phase-scrambling the faces used in the experiment (see Peltola et al. (2008) for details). The faces were pictures of two Black females that had been tested in a small-scale pilot study to look familiar to the local people and provide valid examples of the happy and fearful expressions (Forssman et al., 2017). The second stimulus was a geometric shape (black and white circles or a checkerboard pattern), which was superimposed by a still picture showing the first frame of a child-friendly cartoon animation. When the infant shifted gaze to the lateral image, the still picture turned into a dynamic cartoon animation that played for up to $4000 \mathrm{~ms}$. Trials were presented in a random order and consisted of eight non-face trials and eight face trials (four happy and four fearful) in both sessions. 
Eye tracking data reduction. Time series data $(60 \mathrm{~Hz})$ with information about the onset times of images, $x y$-boundaries of active areas of interest (AOI) on the screen, and $x y$ coordinates of the participants' eyes and their respective validity estimates, as given by the Tobii eye tracker, were stored in Tobii gazedata output files. These data were pre-processed and analyzed offline by using a library of automated MATLAB functions (Leppänen et al., 2015). Data on the $x y$-coordinates corresponding to the two eyes were combined by taking a mean of the coordinates (or by using the eye with valid $x y$-coordinates if one of the coordinates for one of the eyes was invalid), extrapolated to fill missing data points (maximum of $200 \mathrm{~ms}$ ), and median filtered with a moving window of nine samples to remove abrupt technical spike artefacts from the data. In each task, trials that failed to meet predetermined data quality criteria (i.e., violated upper limit of extrapolation) were excluded. Additional task-specific exclusion criteria were applied for the assessment of attentional dwell times in the face task so that trials with $<70 \%$ fixation on the central stimulus prior to attention shift and trials on which the shift occurred during a period of extrapolated data were excluded.

Subsequent to the preprocessing steps, we calculated metrics of infants' eyemovement for each of the three tasks. For the visual search task, we extracted the latency at which the infant's point of gaze first entered the AOI with the red apple. For the anticipatory attention shifts task, we extracted the latency of anticipatory saccades from the central AOI to the "correct" lateral AOI, representing the area where the audiovisual visual stimulus was presented. Anticipatory saccades were defined as saccades that were initiated within a 1150 ms window that started at the onset of the auditory cue and ended $150 \mathrm{~ms}$ after the onset of the lateral stimulus (this time window was used based on previous studies showing that saccades shorter than 150 ms are typically considered anticipatory, not driven by the stimulus). For the attention to faces task, to assess infants' attention to non-face patterns and 
faces, we calculated the duration the infant gaze stayed in the center AOI before an attention shift to the peripheral AOI occurred, or before a time-out period of 3500 ms had elapsed. The duration data were converted into a normalized dwell time index $=\sum_{i=1}^{n}\left(1-\frac{3500-x_{i}}{3500-150}\right)$, where $x$ is the time point of the gaze shift away from the center AOI (i.e., the last time point when gaze is in the area of the first stimulus preceding a saccade towards the lateral stimulus), and $n$ is the number of scorable trials in a given stimulus condition. The shortest acceptable gaze shift latency (150 ms) results in an index value of 0 , and the longest possible latency (or a lack of gaze shift, which is equal to the last measured time point of the first stimulus at $3500 \mathrm{~ms}$ ) in an index value of 1 . Dwell time indices were calculated separately for each of the three stimulus conditions (i.e., non-face, happy, fearful). This approach is comparable to the more commonly used approach for calculating mean saccadic latency or saccadic reaction time measures with the exception that it does not exclude trials without gaze shift (or reaction times censored at the 3500 ms cut-off). It is also noteworthy that the time-out value was raised from the typical $1000 \mathrm{~ms}$ in previous studies using the current methodology to the maximum of $3500 \mathrm{~ms}$ in the Malawian study, given that the dwell times are significantly longer in Malawian infants, and the lower time-out value resulted in a strong ceiling effect.

Aggregation of eye tracking data. For a participant to be included in the analyses of a particular task, the infant needed to provide at least three valid trials for each condition of the task. Thus, the final sample size varies between different eye tracking outcome measures. We computed descriptive statistics from the visual search task for visual search latency (using successful orienting responses in the single-object condition), and for the proportion of successful responses of valid trials in single-object, multiple-objects, and conjunction conditions. From the anticipatory attention shifts task we extracted the proportion of anticipatory saccades on trials 2-8 (pre-switch, preceding stimulus switch) and trials 10-16 
(post-switch, i.e., after the side of the visual stimulus was switched). Trials 1 and 9 were excluded from the proportion as they were not predictable. From the attention to faces task we computed the proportion of attention shifts toward the lateral stimulus in each of the three conditions, and dwell time indices for non-face patterns and happy and fearful faces.

\section{Anthropometric Assessment}

Infant length was assessed using a length board (Harpenden Infantometer, Holtain Limited, Crosswell, Crymych, UK) and recorded to the nearest $1 \mathrm{~mm}$. Infant weight was assessed using an electronic infant weighing scale (SECA 735, Seca GmbH \& Co., Hamburg, Germany) with reading increments of 10 g. Mid-upper arm circumference (MUAC) and head circumference were measured with non-stretchable plastic insertion tapes (ShorrTape, Weigh and Measure, LLC, Olney, MD) and recorded to the nearest $1 \mathrm{~mm}$. All anthropometric measurements were done in triplicate by trained personnel. We used the mean of the first two readings if they did not differ by more than a prespecified tolerance limit (5 mm or $100 \mathrm{~g}$ ). If the difference was above the limit, the third measurement was compared with the first and second measurements, and the pair of measurements that had the smallest difference was used to calculate the mean.

Age- and sex-standardized anthropometric indices (length-for-age, weight-for-age, weight-for-length, and head circumference-for-age z-scores) were calculated using World Health Organization Child Growth Standards (WHO, 2006) for all ages. For the analysis, MUAC was used instead of WHO MUAC-for-age z-scores, as the latter were not available for children younger than 3 months of age. Length measurements at enrollment from Malindi hospital by two data collectors were suspected to have systematic measurement error due to a failure to comply with the standard operating procedures. To take this into account in the analysis, an additional sensitivity analysis with single regression imputation was performed.

\section{Maternal Interviews and Questionnaires}


Mothers were interviewed during the home and clinic visits to collect demographic information, and to assess mothers’ cognitive abilities, psychosocial well-being, socioeconomic status, and child care practices (see Table S1 for the schedule).

Cognition. Mothers completed tests assessing spatial cognition (mental rotation), working memory (digit span forward and backward test), and verbal fluency (listing foods and girls’ names) which have been previously used in the target population (Prado et al., 2018). The mental rotation test consisted of five rows of figures. For each row, the first figure was the original figure and the next eight figures were either rotated or flipped versions of the original figure (Figure S1). The mother was asked to point out the rotated figures (total of 46 in a row). The number of rotated figures correctly identified and the number of flipped figures correctly not identified as rotated were summed to obtain a total test score. On the digit span test, the mother was asked to repeat sequences of digits, increasing in length from two to nine digits. There were two sequences for each length of digits. In the forward condition, the mothers were asked to repeat each digit in the sequence in the presented order. In the backward condition, the mothers were asked to repeat each digit in the sequence in backward order. In both conditions, the test was continued until the mother failed both sequences with a given number of digits, or the maximum length was reached. The total number of correct responses was calculated for each condition. On the verbal fluency test, the mother was first asked to name as many foods as possible in $60 \mathrm{~s}$ and then as many girls' names as possible in $60 \mathrm{~s}$. A total number of unique words was calculated for each category.

Psychosocial well-being. Mothers’ psychosocial well-being was assessed by using four questionnaires, covering depression symptoms, perceived stress, life events, and social support. To assess maternal depression symptoms, 20 yes/no-questions from the selfreporting questionnaire on depression symptoms (WHO, 1994) were used (e.g., loss of appetite, loss of happiness), and the number of positive responses (i.e., responses indicating 
the absence of a particular symptom) were counted for a total depression symptom score. The questionnaire has been validated for use in Malawi (Stewart et al., 2009). Perceived stress was assessed by asking questions about stressful experiences (e.g., How often have you felt that you were unable to control the important things in your life?) (after Cohen, Kamarck, \& Mermelstein, 1983), and scoring the responses on a relevant 5-point scale. The responses were summed for a total stress score. To assess adverse life events, we adapted 17 questions from the Recent Life Events questionnaire (Brugha, Bebington, Tennant, \& Hurry, 1985). The mothers were asked if the event had occurred (e.g., Have any of your immediate family members died?) and, if the event had occurred, whether it still affected the mother (occurrence was scored as 1 and still affecting as 2). The responses were summed for the adverse life events score. Finally, to assess social support, mothers were asked about their perceptions of the availability of a special person or friends to help, talk with, or share emotions with. Each question was answered from a choice of five responses using a response card with visual depictions of strongly disagree, mildly disagree, neutral, mildly agree, and strongly agree (a 5-point scale). Answers were summed to create a total social support score.

Socioeconomic status. Three questionnaires assessed mothers’ socioeconomic status: questions related to the satisfaction of everyday needs, questions concerning food insecurity, and questions related to the living conditions. To assess the satisfaction of everyday needs, mothers were asked about food (e.g., How often did your children eat three meals every day?, How often did you have enough money for everyday needs?) and satisfaction of other everyday needs (e.g., whether the mother had been able to buy food, clothes, and soap for laundry or washing for her or her children, and if she's been working in the past month). Questions about everyday needs were answered with yes or no, and the sum of yes-answers was calculated to form a total score. To assess the household's access to food, the food insecurity access scale (HFIAS) (Coates, Swindale, \& Bilinsky, 2007) questionnaire 
was used. HFIAS consists of nine questions about the household's ability to access food, the variety and amount of food consumed, and the hunger experienced by household members. For each question, the respondent was asked if the event occurred never, rarely, sometimes, or often in the last 30 days (a 4-point scale). Scores were summed to give a total score for household food insecurity which was adjusted to season. Living conditions were assessed by asking questions about the building material of the house and the roof, the main source for drinking water, the sanitary facilities, the light source, and the main source for cooking oil. For each question, response options were ranked, with a higher score indicating more developed living conditions. Based on the collected answers, each question was standardized $(M=0, S D=1)$ to represent the variety of housing conditions. Standardized answers were summed to create a living environment score.

Care practices. Maternal care practices were assessed by using home observations and questions related to mother-infant bonding. The Home Observation for the Measurement of the Environment (HOME) inventory (Caldwell \& Bradley, 2003) has been designed to obtain estimates of the amount and quality of interactions and toys in the child's environment that promote cognitive, motor, and socio-emotional development. Specifically, the interview and observations at participant's home focused on the mother's actions toward and responses to her child (e.g., mother caresses or kisses child at least once during the home visit, mother neither slaps nor spanks the child during the home visit). The form consisted of 36 questions or observations with response options of no and yes, where yes was indicative of a positive outcome. The sum of yes-responses was calculated to represent the home care practices score. The mother's bond to her infant was administered with the Mother-to-Infant Bonding Scale (Taylor, Atkins, Kumar, Adams, \& Glover, 2005). The questionnaire consisted of questions about the mother's feelings for her child in the first few weeks after birth. The mother was asked to state the extent (very much, a lot, a little, not at all, a 4-point scale) that best 
described how she felt when presented with eight different adjectives, for example, joyful, protective, and aggressive. Each response was rated on a scale from 0 to 3, and summed in a way that higher score meant positive feelings.

Aggregation of maternal data. The questionnaire and interview data on maternal characteristics were aggregated by standardizing $(M=0, S D=1)$ the score for each subscale within a domain (e.g., within different tests of maternal cognition), reversing higher score to indicate positive outcomes (e.g., no problems, better facilities), and then taking a sum of the standardized scores within the domain (cognition, psychosocial well-being, socioeconomic status, and care practices).

\section{Statistical Analyses and Power}

The first set of analyses were aimed at replicating the results of previous studies in the current sample. In this analysis, we compared probability of successful responses in singleobject, multiple-objects, and conjunction conditions in the visual search task, probability of anticipatory saccades on pre-switch and post-switch in the anticipatory attention shifts task, as well as the probability of saccades and attentional dwell times for non-face patterns and happy and fearful faces in the attention to faces task. Second, we examined the reliability of individual differences in the key scores for each task. For this analysis, we calculated oddeven split-half correlations separately for the 7 and 9 months data, as well as test-retest correlations of test scores between 7 and 9 months. Finally, we tested whether eye tracking results were related to risk factors for early child development, including GA (shorter GA was considered to be associated with higher risk), markers of nutritional status at birth and at 9 months (i.e., WAZ and LAZ), and measures reflecting infants' early rearing environment (i.e., maternal domains).

To examine associations between eye tracking measures and risk factors (i.e., GA, anthropometric measurements, and rearing environment), we used data from the 9-month 
assessment and focused on the four constructs that the eye tracking tasks were designed to measure: 1) visual search latency using data from the one-object condition, 2) visual search interference using data from the conjunction condition (adjusted to the single-object and multiple-objects conditions), 3) the ability to update anticipatory attention shifts after a change in stimulus contingency (i.e., anticipatory responses on post-switch trials, adjusted to anticipatory responses on pre-switch trials), and 4) dwell time for faces (adjusted to dwell time for non-face control stimuli).

Given that most of the test variables deviated from normal distribution, we used distribution-free statistical test in all analyses with eye tracking scores. Age and condition differences on eye tracking scores were evaluated by using non-parametric paired samples test (Wilcoxon signed-rank test). Comparisons between eye tracking scores and GA categories were performed with Kruskal-Wallis equality-of-populations rank test with ties. All correlations (odd-even, test-retest, and variable comparisons) were calculated as Spearman's rank correlation coefficients for un-adjusted tests and as Spearman’s partial rank correlation coefficients for adjusted tests. Correlation coefficients $>.20$ were considered significant in light of previous association analyses in infants.

The sample size was designed to be sufficient for comparing eye tracking data between full- and preterm infants. The targeted sample size of 425 with a ratio of 1:2:2 for GA groups was designed to provide the study with $80 \%$ power and $95 \%$ confidence to document a statistically significant difference in the eye tracking scores between the preterm and the full term infants, for an effect size in the target population of $0.45 S D$ or larger. Final sample provided corresponding power and confidence for effect sizes of 0.43-0.46 SD, depending on analysis. Other analyses examining associations between eye tracking data (four variables) and distinct aspects of the early nutritional status and rearing environment are presented as exploratory analyses, and were evaluated against a corrected alpha of .0125. 


\section{Results}

\section{Sample Characteristics}

Between November 2014 and October 2015, 1509 mothers were screened for the study (Figure 2). Of these, 444 mothers with their singleton children (29\%) were enrolled. Mothers who were screened, but not included, were not interested in participating in the study ( $n=402)$, did not meet all eligibility criteria $(n=610)$, or were not recruited to meet the stratified sampling ratios $(n=53)$. Of the children who did not meet the eligibility criteria, the reasons for non-eligibility were obstetric ultrasound being carried out too late or not done (64\%), residence outside the study area or not available for follow-up (15\%), gestational age $<32+0$ or $>41+6$ weeks (7\%), non-eligibility for unspecified reasons (7\%), non-singleton pregnancy (5\%), child too old at enrollment (1\%), or illness that prevented participation in the study (0.5\%).

Demographic and anthropometric information for the enrolled children are provided in Tables 1-2. Of the enrolled infants, 229 (52\%) were full term, 145 (33\%) early term, and 70 (16\%) preterm. At enrollment, 24\% of infants were stunted (LAZ < -2) and 10\% underweight (WAZ < -2). At 9 months, 27\% and 11\% were stunted and underweight, respectively. Between enrollment and the 9-month-visit, 34 (8\%) participants were lost to follow-up, or died (Figure 2). Infants who were lost to follow-up had smaller head size at enrollment than infants continuing in the study at 9 months (difference in head circumference-for-age $z$-score $=-0.51, p=.007$ ), whereas there was no statistically significant difference in LAZ, WAZ, or maternal age. Parental literacy rates were lower and parental employment rates at the same level or higher in the current samples as compared to the national average for rural Malawi (Table 1). Further sample characteristics are shown in Table S2. 
At 7 and 9 months, 395 (96\%) and 384 (97\%) infants who visited the clinic had valid data from at least one of the subtests (visual search, anticipatory attention shifts, or attention to faces). Infants who were included in the eye tracking analysis did not differ in background variables from the infants with not enough valid data at 9 months (data not shown). The range of participants with a valid task by condition was 312-376 (76-91\%) at 7 months and 312-365 (79-92\%) at 9 months.

\section{Descriptive Data for Eye Tracking Tests}

Descriptive data for the eye tracking tests are provided in Table 3. The proportion of successful visual search tasks was highest in the one-object condition, $(M=91.8 \%, S D=$ 15.9), second highest in the multiple-objects condition $(M=61.8 \%, S D=21.6)$, and lowest in the conjunction condition $(M=45.4 \%, S D=20.4)$ at 9 months. The differences between conditions were significant $(p s<.001)$. Anticipatory responses increased over the course of the anticipatory attention shifts task (Figure 3), and the proportion of successful anticipation was higher on the pre-switch trials $(M=72.0 \%, S D=26.5)$ than on the post-switch trials $(M$ $=54.2 \%, S D=28.4)(p<.001)$. Finally, the mean proportion of trials with an attention shift from the central to the lateral stimulus was higher in the non-face control condition $(M=$ $99.7 \%, S D=2.0)$ as compared to the happy face condition $(M=71.2 \%, S D=25.8)$ and fearful face $(M=66.7 \%, S D=26.3)(p s<.001)$, and the difference between happy and fearful faces was also statistically significant $(p=.002)$. Similar results were obtained when dwell time index (instead of the proportion of attention shifts) was used as the dependent variable, with shortest dwell time indices in the non-face control condition $(M=.12, S D=$ $0.04)$ as compared to happy $(M=.53, S D=0.22)$ and fearful $(M=.57, S D=0.22)$ face conditions.

The robustness of infants' attentional bias for faces is further illustrated in Figure 4. All individual infants demonstrated this bias (i.e., shorter dwell times for non-face patterns 
than faces). Also, showing the specificity of infants' attentional bias for faces, the dwell times for non-face patterns and faces were only poorly correlated $\left(r_{\mathrm{s}}=.20\right)$, whereas the dwell times in the two face conditions (happy vs. fear) were strongly correlated $\left(r_{\mathrm{s}}=.63\right)$.

\section{Age Differences}

Visual search latencies were longer at 7 months as compared to 9 months (Table 3). The proportion of successful search responses did not, however, differ between 7 and 9 months in any of the three conditions. The proportion of anticipatory responses increased between 7 and 9 months in the pre- and post-switch trials. Finally, there were no age differences in the proportion of attention shifts between 7 and 9 months in the non-face control condition, but in the two face conditions attention shifts were higher at 9 months.

\section{Individual Differences}

Odd-even split-half correlations were low to moderate for all measures, with highest correlations observed in the anticipatory attention shifts task followed by dwell times for faces (Table 4). The pattern of odd-even split-half correlations did not differ between the 7and 9-month assessments. Similar to the odd-even split-half correlations, the test-retest correlations between 7- and 9-month eye tracking results were generally low, with highest test-rest correlations for the dwell time index on faces. The odd-even split-half and test-retest correlation coefficients remained relatively unchanged when the inclusion criteria for the number of valid trials per condition was increased, although incremental improvements in the coefficient were found for some of the measures (Tables S3-S4).

\section{Association with Risk Factors}

There were no significant differences in any of the eye tracking scores at 9 months and GA groups, or correlations between eye tracking scores at 9 months and GA (Table 5), anthropometric measurements at birth or at 9 months (Table 6), or any of the maternal variables (Table 7). This result did not change when using 7- instead of 9-month-data, when 
nutritional status was measured by using other anthropometric indicators, or when enrollment length values were imputed (Tables S5-S9). In additional analyses, correlation coefficients between eye tracking results and risk factors remained relatively unchanged when the criteria of the number of valid trials per condition was increased (Tables S10-S11). Also, the associations between dwell time for faces and risk factors varied a maximum of |.08| in absolute values when the dwell times were calculated without the censored (3500 ms) values (data not shown).

\section{Discussion}

The present study examined the development of visual attention capabilities in a large sample of infants living in rural settings in Malawi. Consistent with prior research in Western countries and a previous study in Malawi (Forssman et al., 2017), the results showed the predicted pattern of results at group level in tasks assessing visual search, anticipatory attention shifts, and attention to faces. The results also showed that there are changes in most of these measures between 7 and 9 months, consistent with the prediction that the measures are sensitive to development of visual attentional processes. In particular, visual search latencies declined over time and the frequency of anticipatory attention shifts increased, consistent with age-related changes in the efficiency of visual orienting (Rose, Feldman, \& Jankowski, 2003). The dwell time for faces also declined, a finding that is consistent with previous studies showing that the dwell times peak at around 7 months and decline thereafter (Peltola et al., 2013). Together, these results provide an important extension of studies that have been primarily conducted in Western, educated, industrialized, and rich countries (Nielsen et al., 2017) to a Sub-Saharan African infant population. The consistency of the patterns adds to the generalizability of the measured abilities in infants.

Our study did not include data from a high-resource laboratory, but previous studies (Forssman et al., 2017) have shown that compared to Finnish infants, Malawian infants have 
slower visual search latencies (consistent with results by Rose, 1994) and are more likely to hold their attention on faces. To further illustrate the latter result, we present data from 9month-old infants from an identical setting from Finland and Malawi (adapted from Forssman et al., 2017) as well as the current results in Figure 5. It can be seen that Finnish and Malawian infants have similar dwell time for non-face patterns but differ drastically in the dwell times for faces. Given that the data for these comparisons were obtained by using the same equipment and procedures (Forssman et al., 2017), and while matching the properties of the non-face patterns and faces, the selectively longer dwell times for faces in Malawi cannot be attributed to procedural differences between the sites or low-level stimulus properties (i.e., stimulus size, color, luminance, or contrast). Different face models were used in Finland and Malawi, but it appears unlikely that that the relatively large differences in dwell times between the two countries would be completely explained by the use of different models, or by variations in facial features or second-order relations among facial features in the models. An alternative possibility is that these results arise from infants' differential experiences in seeing stimuli on computer displays. However, this explanation falls short in explaining the fact that the country difference was selectively pronounced in the face conditions.

If longer dwell times for faces in Malawian infants is not explained by the features of the stimuli or familiarity with computer displays, the possibility arises that this result reflects a genuine enhancement of attention to salient stimuli in infants in low-resource settings. Our current results do not provide direct support for this possibility, but previous research in highresource settings have shown heightened attention to visual salience, especially faces displaying threat-alerting expressions, in infants whose mother reported elevated stress and depression symptoms (Forssman et al., 2014; Kataja et al., in press; Morales et al., 2017; although see Leppänen, Cataldo, Bosquet Enlow, \& Nelson, 2018). 
Whereas our results show reproducibility of infants' attentional phenomena at group level, the measured behaviors varied considerably within individual infants across separate measurements. In particular, our results show that individual variations in the proportion of successful search responses and anticipatory responses were not stable across time. Attentional dwell times for faces showed moderate stability across a two-month-interval, the correlations being comparable to those reported in a previous study from high resource settings (Leppänen et al., 2015). Part of the within-subject variability in the measures of interest is likely to be instrumental and related to the challenges in obtaining sufficient sampling of the target behaviors for all infants. However, given that our estimates of instrumental reliability (i.e., odd-even split-half correlations) were consistently higher than estimates of test-retest stability, it seems likely there are also true changes in the measured behaviors over time. Together, this result has important implication for the use of these measures as markers of early neurocognitive development. Most notably, analyses examining associations between infant neurocognitive function and variables characterizing infants’ rearing environment should take into account the noise in the measurements and the implications it has on the expected strength of the associations.

Contrary to the expectations, individual variations in attention measures were not associated with gestational age, nutritional status, or characteristics of the rearing environment. In other words, visual search, anticipation, or the duration of attentional dwell on faces did not vary in full- and preterm infants, in infants of varying nutritional status, or in infants living in heterogeneous rearing environments as assessed by socioeconomic status, maternal cognition, maternal psychosocial well-being or care practices.

One possibility is that the current results underestimate the true association between measures of infant attention and various risk factors, given measurement error. This is a reasonable concern, especially for associations concerning measures of visual search and 
anticipation. For measures of attention to faces, the odd-even split-half and test-retest correlations were moderate. The mean true reliability for dwell time estimates for faces, after applying the Spearman-Brown correction for the odd-even split-half correlations (Wilmer, 2008), was .77. To assess how potential associations were attenuated by measurement error, the observed correlations between measures of infant dwell times for faces and risk factors (< |0.12|) can be scaled for measurement error by dividing the correlation by the geometric mean of the estimated reliabilities of the two measures being correlated (Spearman, 1904; Wilmer, 2008). After this correction, the correlation coefficients remain low. It therefore seems that the lack of the predicted association between eye tracking measures and risk factors is not completely attributable to measurement noise.

If the current results reflect a true lack of associations between infants' attention and measures of gestational age, nutritional status, and various socioeconomical risk factors, the possibility arises that the development of the measured aspects of infant behavior is relatively robust against variations in early environment. This interpretation of the current findings must be made with caution, however. First, the current sample differed from previous studies in high-resource settings in that the highest risk infants were not included (or were possibly underrepresented) in the current sample, such as infants with extreme preterm birth (i.e., $<32$ weeks) or infants with neurological deficits (e.g., Atkinson et al., 2008; Telford et al., 2016). Also, only a minority of infants in the current study were classified as moderately malnourished, suggesting that the full spectrum of variations in nutritional status were not included. Full comparisons of the socioeconomic risk scores in the current sample with respect to national average in Malawi were not available, but parental literacy rates were lower in the current sample, and parental employment rates slightly higher compared to the average for rural Malawi. Finally, it remains possible that even if the early attentional capacities of infants, as measured here, may emerge relatively independently of variations in 
the early environment, the possibility remains that the more complex functions that emerge downstream in early development (i.e., construct assessed by traditional cognitive and behavioral tests) are more dependent on “optimal” physical growth and environmental support or stimulation.

In summary, the current study replicated previous studies in high-resource settings in so far understudied population, by showing that Malawian infants exhibited active visual search for salient visual targets, anticipatory saccades to predictable events, and a robust attentional bias for faces. The results further showed that while these behaviors were reproducible at group level, the stability of individual infants' behaviors was poor within short time intervals, and there were no association between the speed or the rate of the measured behaviors and infants' gestational age, nutritional status, or rearing environment. 


\section{References}

Ahtola, E., Stjerna, S., Yrttiaho, S., Nelson, C. A., Leppänen, J.M., \& Vanhatalo, S. (2014). Dynamic eye tracking based metrics for infant gaze patterns in the face-distractor competition paradigm. PLoS One, 9(5), e97299.

Amso, D., Haas, S., \& Markant, J. (2014). An eye tracking investigation of developmental change in bottom-up attention orienting to faces in cluttered natural scenes. PLoS One, 9(1), e85701.

American College of Obstetricians and Gynecologists (ACOG). (2013) Definition of term pregnancy. Committee Opinion No. 579. Obstetrics \& Gynecology, 122, 1139-40.

Atkinson, J., Braddick, O., Anker, S. Nardini, M., Birtles, D., Rutherford, M.A., ...Cowan, F.M. (2008). Cortical vision, MRI and developmental outcome in preterm infants. Archives of Disease in Childhood - Fetal and Neonatal Edition, 93(4), F292-297.

Bedford, R., Pickles, A., Sharp, H., Wright, N., \& Hill, J. (2015). Reduced face preference in infancy: A developmental precursor to callous-unemotional traits? Biological Psychiatry, 78(2), 144-150.

Brugha, T., Bebington, P., Tennant, C., \& Hurry, J. (1985). The list of threatening experiences: A subset of 12 life events categories with considerable long-term contextual threat. Psychological Medicine, 15, 189-194.

Butcher, P.R., Kalverboer, A.F., Geuze, R.H., \& Stremmelaar, E.F. (2002). A longitudinal study of the development of shifts of gaze to a peripheral stimulus in preterm infants with transient periventricular echogenicity. Journal of Experimental Child Psychology, 82(2), 116-140.

Caldwell, B.M., \& Bradley, R.H. (2003). Home Observation for Measurement of the Environment: Administration Manual. Tempe, AZ: Family \& Human Dynamics Research Institute, Arizona State University. 
Champakam, S., Srikantia, S. G., \& Gopalan, C. (1968). Kwashiorkor and mental development. The American Journal of Clinical Nutrition, 21, 844-855.

Coates, J., Swindale, A., \& Bilinsky, P. (2007). Household Food Insecurity Access Scale (HFIAS) for Measurement of Household Food Access: Indicator Guide (v. 3). Washington, DC: FHI 360/FANTA.

Cohen, S., Kamarck, T., \& Mermelstein, R. (1983). A global measure of perceived stress. Journal of Health and Social Behavior, 24(4), 385-396.

Cousijn, J., Hessels, R.S., Van der Stigchel, S., \& Kemner, C. (2017). Evaluation of the psychometric properties of the gap-overlap task in 10-month-old infants. Infancy, 2(4), 571-57

de Jong, M., Verhoeven, M., \& van Baar, A.L. (2015). Attention capacities of preterm and term born toddlers: A multi-method approach. Early Human Development, 91(12), 761-768.

Foreman, N., Fielder, A., Price, D., \& Bowler, V. (1991). Tonic and phasic orientation in full-term and preterm infants. Journal of Experimental Child Psychology, 51(3), 407422.

Forssman, L., Ashorn, P., Ashorn, U., Maleta, K., Matchado, A., Kortekangas, E., \& Leppänen, J.M. (2017). Eye-tracking-based assessment of cognitive function in lowresource settings. Archives of Disease in Childhood, 102(4), 301-302.

Forssman, L., Peltola, M.J., Yrttiaho, S., Puura, K., Mononen, N., Lehtimäki, T., \& Leppänen, J.M. (2014). Regulatory variant of the TPH2 gene and early life stress are associated with heightened attention to social signals of fear in infants. Journal of Child Psychology and Psychiatry, 55(7), 793-801.

Frank, M.C., Vul, E., \& Johnson, S.P. (2009). Development of infants' attention to faces during the first year. Cognition, 110(2), 160-170. 
Galler, J.R., Bryce, C.P., Zichlin, M.L., Waber, D.P., Exner, N., Fitzmaurice, G.M., \& Costa, P.T. (2013). Malnutrition in the first year of life and personality at age 40. Journal of Child Psychology and Psychiatry, 54(8), 911-919.

Gillespie-Smith, K., Boardman, J.P., Murray, I.C., Norman, J.E., O'Hare, A., \& FletcherWatson, S. (2016). Multiple measures of fixation on social content in infancy: Evidence for a single social cognitive construct? Infancy, 21(2), 241-257.

Gluckman, M., \& Johnson, S.P. (2013). Attentional capture by social stimuli in young infants. Frontiers in Psychology, 4, 527.

Hackman, D.A., Gallop, R., Evans, G.W., \& Farah, M.J. (2015). Socioeconomic status and executive function: Developmental trajectories and mediation. Developmental Science, 18(5), 686-702.

Hunnius, S., Geuze, R.H., \& Geert, P. v. (2006). Associations between the developmental trajectories of visual scanning and disengagement of attention in infants. Infant Behavior and Development, 29, 108-125.

Hunnius, S., Geuze, R. H., Zweens, M.J., \& Bos, A.F. (2008). Effects of preterm experience on the developing visual system: A longitudinal study of shifts of attention and gaze in early infancy. Developmental Neuropsychology, 33(4), 521-535.

Itti, L., \& Koch, C. (2001). Computational modelling of visual attention. Nature Reviews.Neuroscience, 2(3), 194-203.

Kaldy, Z., Kraper, C., Carter, A.S., \& Blaser, E. (2011). Toddlers with autism spectrum disorder are more successful at visual search than typically developing toddlers. Developmental Science, 14(5), 980-988.

Kataja, E.-L., Karlsson, L., Leppänen, J.M., Pelto, J., Häikiö, T., Nolvi, S., ...Karlsson, H. (in press). Maternal depressive symptoms during the pre- and postnatal periods and infant attention to emotional faces. Child Development. 
Klein, C., \& Fischer, B. (2005). Instrumental and test-retest reliability of saccadic measures. Biological Psychology, 68(3), 201-13.

Klin, A., Shultz, S., \& Jones, W. (2015). Social visual engagement in infants and toddlers with autism: Early developmental transitions and a model of pathogenesis. Neuroscience \& Biobehavioral Reviews, 50(0), 189-203.

Kovács, Á.M., \& Mehler, J. (2009). Cognitive gains in 7-month-old bilingual infants. Proceedings of the National Academy of Sciences, 106, 6556-60.

Kulke, L., Atkinson, J., \& Braddick, O. (2015). Automatic detection of attention shifts in infancy: Eye tracking in the fixation shift paradigm. PLoS One, 10(12), e0142505.

Landry, S.H., Leslie, N.A., Fletcher, J.M., \& Francis, D.J. (1985). Visual attention skills of premature infants with and without intraventricular hemorrhage. Infant Behavior and Development, 8(3), 309-321.

Leppänen, J.M. (2016). Using eye tracking to understand infants' attentional bias for faces. Child Development Perspectives, 10(3), 161-165.

Leppänen, J.M., Cataldo, J., Bosquet Enlow, M., \& Nelson, C.A. (2018). Early development of attention to threat-related facial expressions. PLoS ONE, 13(5), e0197424.

Leppänen, J.M., Forssman, L., Kaatiala, J., Yrttiaho, S., \& Wass, S. (2015). Widely applicable MATLAB routines for automated analysis of saccadic reaction times. Behavior Research Methods, 47(2), 538-548.

Leppänen, J.M., Peltola, M.J., Puura, K., Mäntymaa, M., Mononen, N., \& Lehtimäki, T. (2011). Serotonin and early cognitive development: variation in the tryptophan hydroxylase 2 gene is associated with visual attention in 7-month-old infants. Journal of Child Psychology and Psychiatry, 52(11), 1144-52.

Matsuzawa, M., \& Shimojo, S. (1997). Infants' fast saccades in the gap paradigm and development of visual attention. Infant Behavior and Development, 20(4), 449-455. 
Morales, S., Brown, K.M., Taber-Thomas, B.C., LoBue, V., Buss, K.A., \& Pérez-Edgar, K.E. (2017). Maternal anxiety predicts attentional bias towards threat in infancy. Emotion, 17(5), 874-883.

National Statistical Office of Malawi (NSO), Malawi in Figures 2016, Retrieved August 14, 2018, from Government of Malawi, National Statistical Office website http://www.nsomalawi.mw/images/stories/data_on_line/general/malawi_in_figures/M alawi\%20in\%20Figures\%202016(1).pdf.

Nielsen, M., Haun, D., Kärtner, J., \& Legare, C.H. (2017). The persistent sampling bias in developmental psychology: A call to action. Journal of Experimental Child Psychology, 162, 31-38.

Pel, J.J.M., Dudink, J., Vonk, M., Plaisier, A., Reiss, I. K.M., \& van der Stehen, J. (2016). Early identification of cerebral visual impairments in infants born extremely preterm. Developmental Medicine \& Child Neurology, 58(10), 1030-1035.

Peltola, M.J., Forssman, L., Puura, K., IJzendoorn, M.H. v., \& Leppänen, J.M. (2015). Attention to faces expressing negative emotion at 7 months predicts attachment security at 14 months. Child Development, 86(5), 1321-1332.

Peltola, M.J., Hietanen, J.K., Forssman, L., \& Leppänen, J.M. (2013). The emergence and stability of the attentional bias to fearful faces in infancy. Infancy, 18(6), 905-926.

Peltola, M.J., Leppänen, J M., Palokangas, T., \& Hietanen, J.K. (2008). Fearful faces modulate looking duration and attention disengagement in 7-month-old infants. Developmental Science, 11(1), 60-68.

Prado, E.L., Ashorn, U., Phuka, J., Maleta, K., Sadalaki, J., Oaks, B.M., ...Dewey, K.G. (2018). Associations of maternal nutrition during pregnancy and post-partum with maternal cognition and caregiving. Maternal and Child Nutrition, 14(2), e12546. 
Rose, S.A. (1994). Relation between physical growth and information processing in infants born in India. Child Development, 65(3), 889-902

Rose, S.A., Feldman, J.F., Jankowski, J.J., \& Caro, D.M. (2002). A longitudinal study of visual expectation and reaction time in the first year of life. Child Development, 73(1), $47-61$.

Rose, S.A., Feldman, J.F., \& Jankowski, J.J. (2003). The building blocks of cognition. The Journal of Pediatrics, 143(4), 54-61.

Rose, S.A., Feldman, J.F., \& Jankowski, J.J. (2012). Implications of infant cognition for executive functions at age 11. Psychological Science, 23(11), 1345-55.

Shah, D K., Guinane, C., August, P., Austin, N.C., Woodward, L.J., Thompson, D.K., ... Inder, T.E. (2006). Reduced occipital regional volumes at term predict impaired visual function in early childhood in very low birth weight infants. Investigative Ophthalmology \& Visual Science, 47(8), 3366-3373.

Spearman, C. (1904). The proof and measurement of association between two things. American Journal of Psychology, 15, 72-101.

Stewart, R.C., Kauye, K., Umar, E., Vokhiwa, M., Bunn, J., Fitzgerald, M., ...Creed, F. (2009). Validation of a Chichewa version of the Self-Reporting Questionnaire (SRQ) as a brief screening measure for maternal depressive disorder in Malawi, Africa. Journal of Affective Disorders, 112(1-3), 126-134.

Sudfeld, C.R., McCoy, D.C., Danaei, G., Fink, G., Ezzati, M., Andrews, K.G., \& Fawzi, W.W. (2015). Linear growth and child development in low- and middle-income countries: a meta-analysis. Pediatrics, 135(5), e1266-75.

Taylor, A., Atkins, R., Kumar, R., Adams, D., \& Glover, V. (2005). A new Mother-to-Infant Bonding Scale: links with early maternal mood. Archives of Women's Mental Health, $8(1), 45-51$. 
Telford, E.J., Fletcher-Watson, S., Gillespie-Smith, K., Pataky, R., Sparrow, S., Murray, I.C., ...Boardman, J.P. (2016). Preterm birth is associated with atypical social orienting in infancy detected using eye tracking. Journal of Child Psychology and Psychiatry, 57(7), 861-868.

Thompson, L., Peñaloza, R.A., Stormfields, K., Kooistra, R., Valencia-Moscoso, G., Muslima, H., \& Khan, N.Z. (2015). Validation and adaptation of rapid neurodevelopmental assessment instrument for infants in Guatemala. Child: Care, Health and Development, 41(6), 1131-1139.

Tsao, D.Y., Schweers, N., Moeller, S., \& Freiwald, W.A. (2008). Patches of face-selective cortex in the macaque frontal lobe. Nature Neuroscience, 11(8), 877.

Valenza, E., Otsuka, Y., Bulf, H., Ichikawa, H., Kanazawa, S., \& Yamaguchi, M.K. (2015). Face orientation and motion differently affect the deployment of visual attention in newborns and 4-month-old infants. PLoS One, 10(9), e0136965.

Walker, S.P., Wachs, T.D., Grantham-McGregor, S., Black, M.M., Nelson, C.A., Huffman, S L., ...Richter, L. (2011). Inequality in early childhood: Risk and protective factors for early child development. The Lancet, 378(9799), 1325-1338.

Weaver, M., \& Lauwereyns, J. (2011). Attentional capture and hold: The oculomotor correlates of the change detection advantage for faces. Psychological Research, 75(1), $10-23$.

Wilmer, J. (2008). How to use individual differences to isolate functional organization, biology, and utility of visual functions; with illustrative proposals for stereopsis. Spatial Vision, 21(6), 561-579.

World Health Organization (WHO). (1994). A User’s Guide To The Self Reporting Questionnaire (SRQ). 
World Health Organization (WHO) Multicentre Growth Reference Study Group. (2006). Child Growth standards based on length/height, weight and age. Acta Paediatrica Supplemental, 450, 76-85.

Yrttiaho, S., Forssman, L., Kaatiala, J., \& Leppänen, J.M. (2014). Developmental precursors of social brain networks: The emergence of attentional and cortical sensitivity to facial expressions in 5 to 7 months old infants. PLoS One, 9(6), e100811. 
Figures

Figure 1. Visualization of the eye tracking tasks. For the visual search task, three conditions were presented. For the anticipatory attention shifts task and the attention to faces task arrows show timeline of occurring items.

\section{Visual search task}

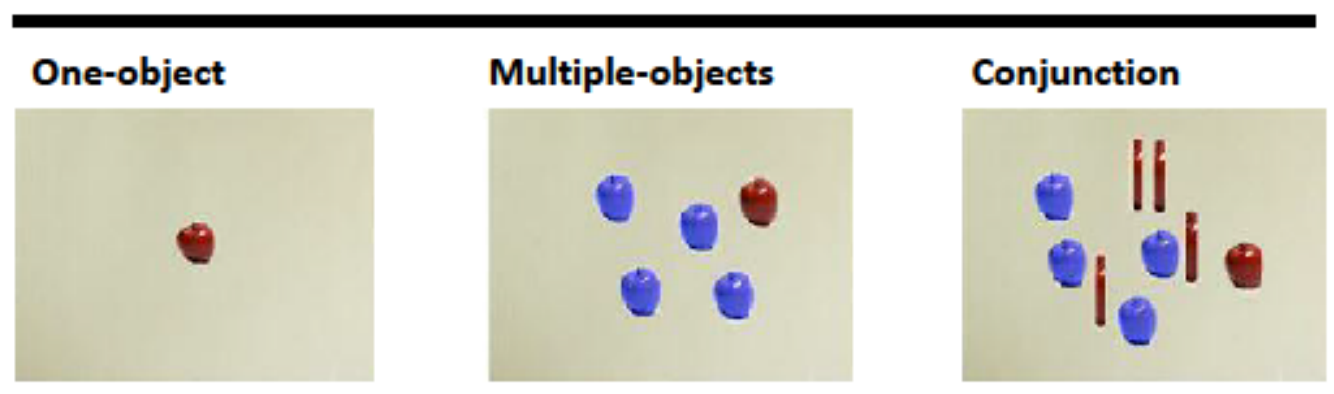

Anticipatory attention shifts task

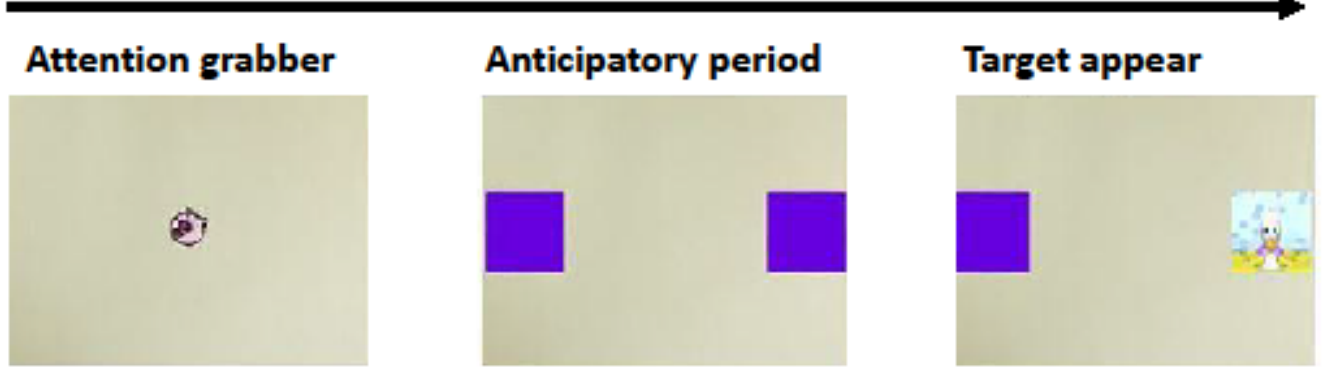

Attention to faces task

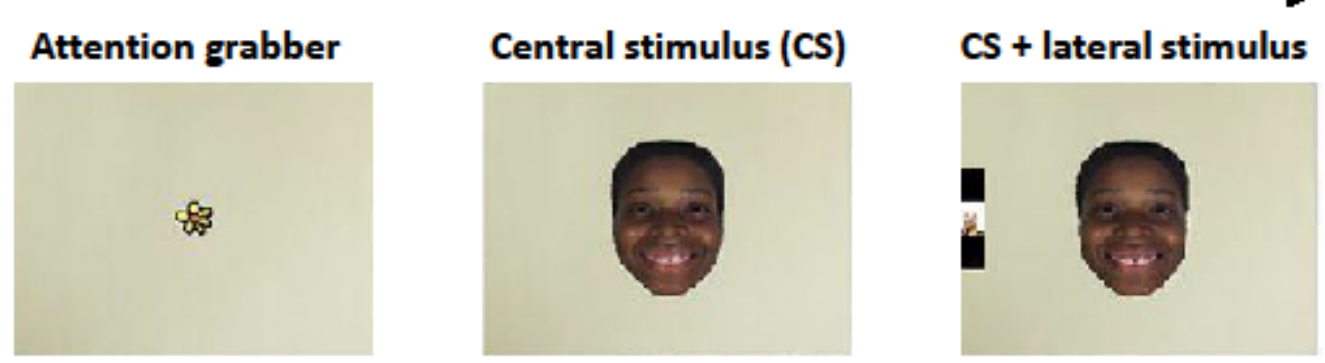


Figure 2. Flow chart of the study.

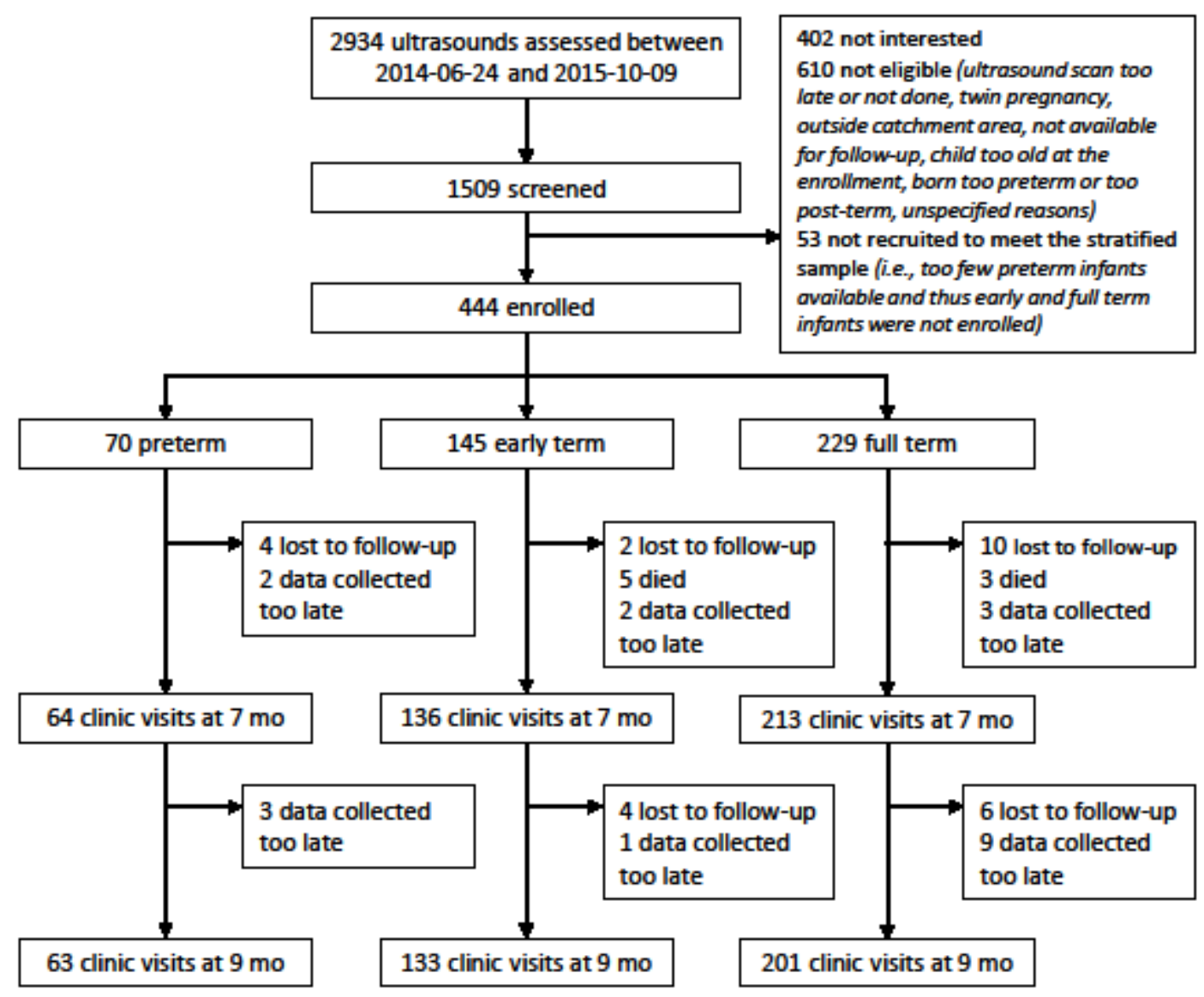


Figure 3. Correct anticipatory means at 7 and 9 months of age for the anticipatory attention shifts task. Lines represent anticipatory periods. The side switch of the stimulus at the trial 9.

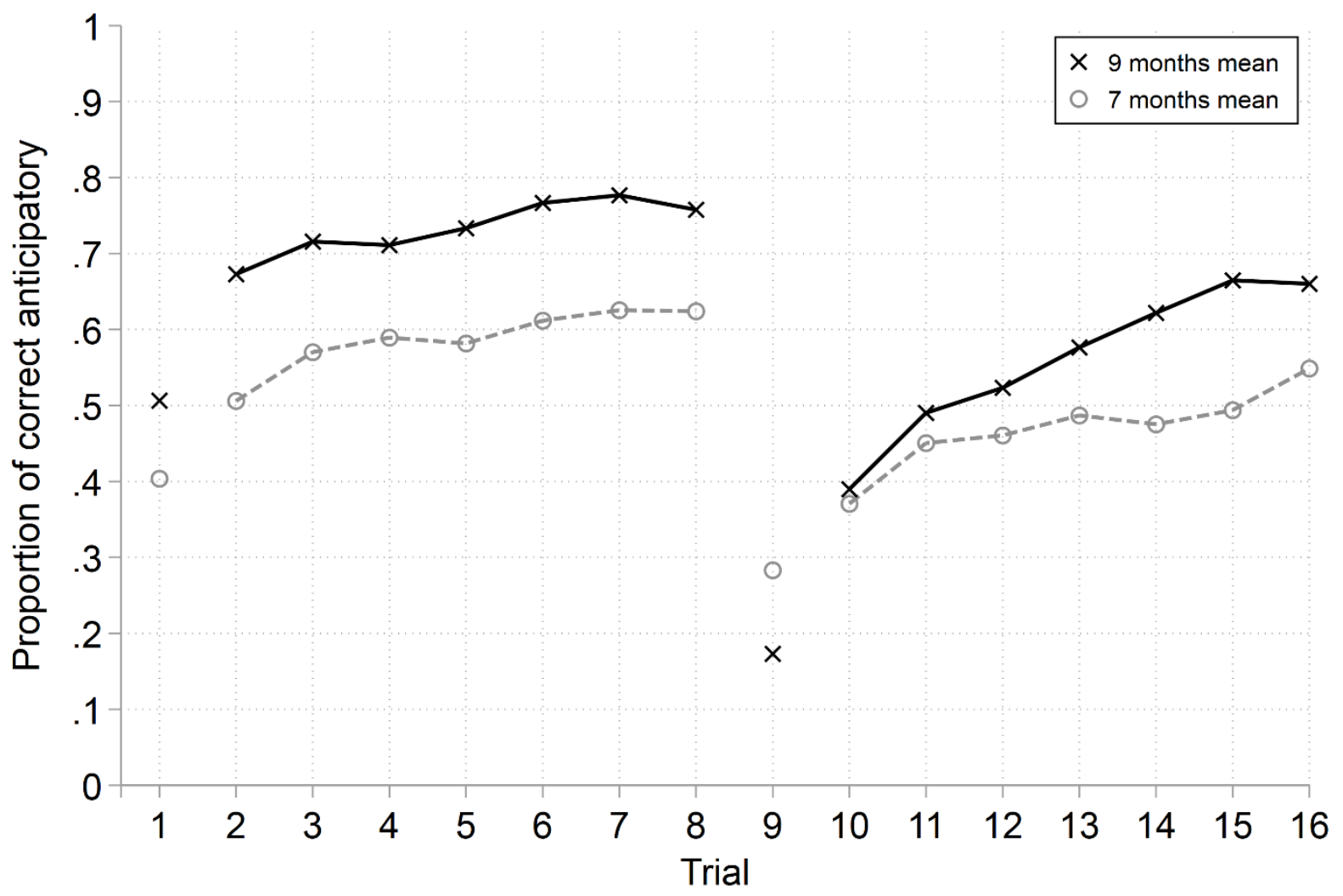


Figure 4. Scatter plot for dwell time index (proportion of time window indicated in parenthesis) on faces and on non-face control stimuli at 9 months of age. $N=312$. Spearman's correlation coefficient $=.20$. Solid grey line represents ms to ms equality. Dashed grey line is LOWESS fit (bandwidth $=0.8$ ).

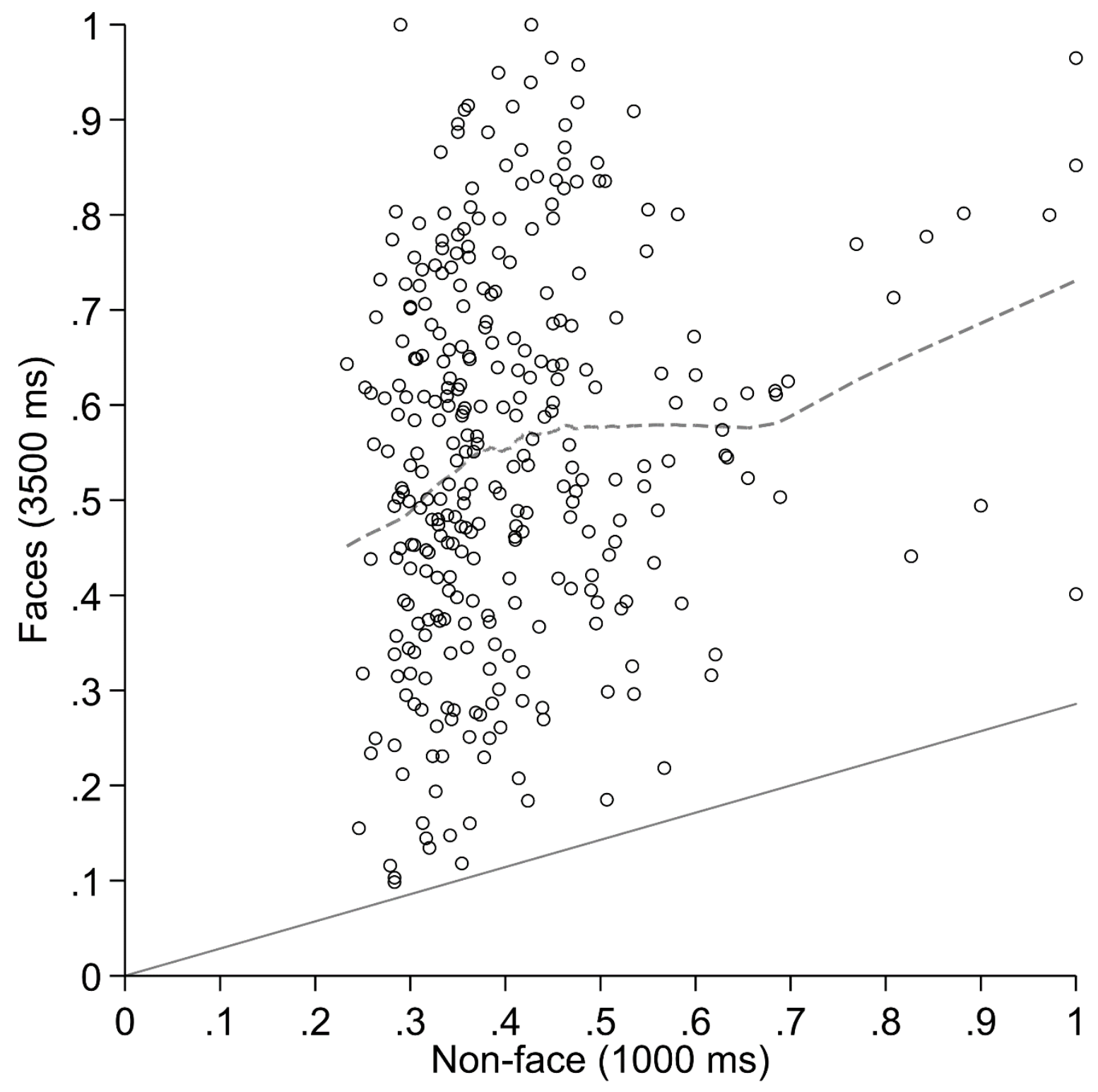


Figure 5. Dwell time means (ms) across Malawian and Finnish settings at 9 months of age from the current study and adapted from Forssman et al. (2017). Bandwidths: non-face = 250, faces $=500 . N=39,37,312 ; M$ (non-face/faces) $=401 / 1028,423 / 1845,410 / 1919 ; S D$ (nonface/faces) = 181/598, 145/739, 141/704 for Finland (Forssman et al., 2017), Malawi (Forssman et al., 2017), and Malawi (current study), respectively.

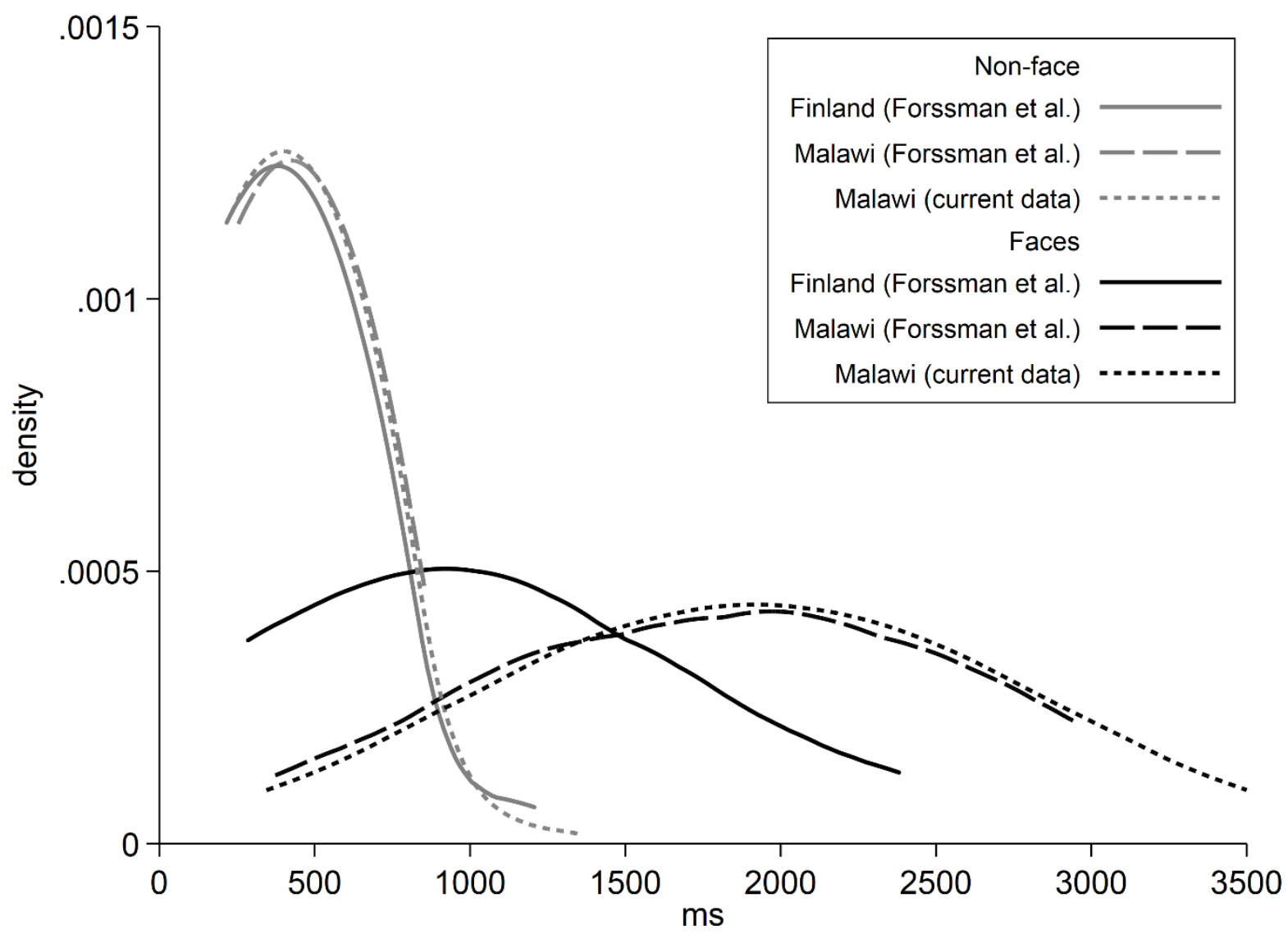


Tables

Table 1. Background variables of enrolled participants’ families.

\begin{tabular}{|c|c|c|c|}
\hline Characteristic & $N$ & Mean (SD) or \% & $\begin{array}{c}\text { Census Data, } \\
\text { Rural } \dagger\end{array}$ \\
\hline Mother's age, y & 444 & $24(7)$ & \\
\hline Father's age, y & 422 & $31(9)$ & \\
\hline Mother's years in school, y & 424 & $3.2(3.2)$ & \\
\hline Father's years in school, y & 410 & $4.8(3.9)$ & \\
\hline Mother’s literacy, \% & 424 & 35.4 & 59.8 \\
\hline Father’s literacy, \% & 423 & 61.0 & 77.7 \\
\hline Mothers not having job, \% & 424 & 22.6 & 23.9 \\
\hline Fathers not having job, \% & 424 & 2.6 & 13.8 \\
\hline Primiparous women, \% & 444 & 29.1 & \\
\hline Children alive (born to mother) & 444 & $2.9(1.8)$ & \\
\hline $\begin{array}{l}\text { Children under-5 living in the } \\
\text { household }\end{array}$ & 424 & $1.7(0.7)$ & \\
\hline People living in the household & 424 & $5.2(1.9)$ & \\
\hline Maternal height & 444 & $155.8(5.6)$ & \\
\hline Maternal BMI at enrollment & 444 & $22.4(2.7)$ & \\
\hline
\end{tabular}

† Source: National Statistical Office of Malawi, Malawi in Figures 2016 (NSO, 2016). 
Table 2. Anthropometric measurements of children

\begin{tabular}{lccc}
\hline Characteristic & Enrollment & 7 months & 9 months \\
\hline$N$ & 444 & 413 & 397 \\
Age at measurement, d & $7(8)^{\dagger}$ & $210(3)$ & $275(4)$ \\
Length, cm & $48.1(2.8)$ & $65.0(2.3)$ & $67.8(2.4)$ \\
Weight, g & $3091(505)$ & $7468(923)$ & $7939(958)$ \\
Mid-upper-arm circumference, cm & $10.3(0.8)$ & $14.2(1.07)$ & $14.3(1.1)$ \\
Head circumference, cm & $34.8(1.5)$ & $42.9(1.3)$ & $43.7(1.3)$ \\
Length-for-age z-score & $-1.34(1.24)^{\ddagger}$ & $-1.39(0.97)$ & $-1.45(0.98)$ \\
Weight-for-age z-score & $-0.86(0.94)$ & $-0.58(1.01)$ & $-0.72(1.01)$ \\
Weight-for-length z-score & $0.03(1.05)$ & $0.43(0.98)$ & $0.16(0.96)$ \\
Head circumference-for-age $z$-score & $\left(N=394^{\S}\right)$ & & $-0.52(0.94)$ \\
Length-for-age z-score $<-2, \%$ & $-0.06(1.07)$ & $-0.35(0.97)$ & 27.5 \\
Weight-for-age z-score $<-2, \%$ & $23.9^{\ddagger}$ & 27.4 & 11.1 \\
\hline
\end{tabular}

$\dagger$ Values are mean (SD) unless percentages.

$\ddagger$ In sensitivity analysis with imputed values for two data collectors LAZ at enrollment was $-1.18(0.98)$ and the proportion of LAZ $<-2$ at the enrollment was $18.1 \%(N=438)$.

$\S$ Fifty measurements out of reference chart for weight-for-length $z$-score (length $<45 \mathrm{~cm}$ ). 
Table 3. Eye tracking variables by participants

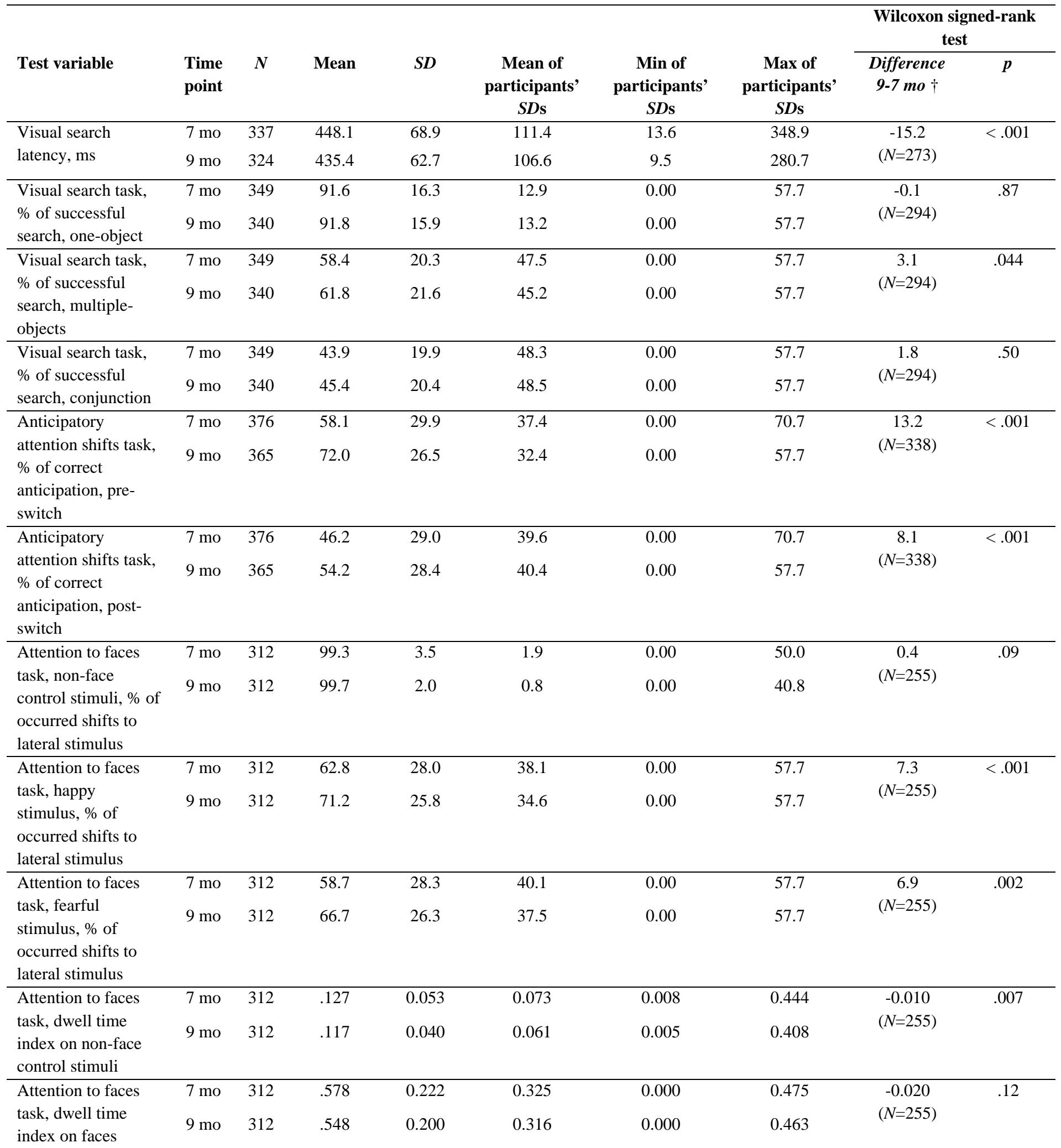

† Only participants with both 7- and 9-month-data. 
Table 4. Odd-even split-half and test-retest Spearman's rank correlation coefficients for eye tracking results

Odd-even split-half tests $\dagger$

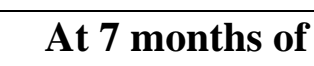

Test variable

Visual search latency

Visual search task, \% of successful search, conjunction

Anticipatory attention shifts task, \% 368 of correct anticipation, post-switch

Attention to faces task, dwell time 359 .62 351 .55 255 .44 index on faces

Test-retest $\ddagger$

7 vs. 9 months of

$\frac{\text { age }}{N \quad r_{s}}$

$273 \quad .28$

294

.20

$319 \quad-.06$

.66 360

.62

338

.07

$\dagger$ Participants with at least two odd and two even trials were included in the analysis of oddeven split-half correlations.

$\ddagger$ Using same inclusion criteria as main analyses. Participant with three or more valid trials at both time points were included in the analysis. 
Table 5. Eye tracking results at 9 months of age by gestational age at birth (GA)

Mean (SD) for the indicated test variable in participant subgroups

\begin{tabular}{|c|c|c|c|c|c|c|}
\hline Test variable & $N$ & $\begin{array}{l}\text { Correlation } \\
\text { coefficient } \\
\text { between the } \\
\text { indicated test } \\
\text { variable and GA } \\
\quad \dagger\end{array}$ & $\begin{array}{l}\text { Infants } \\
\text { born } \\
\text { preterm }\end{array}$ & $\begin{array}{c}\text { Infants } \\
\text { born early } \\
\text { term }\end{array}$ & $\begin{array}{c}\text { Infants born } \\
\text { full term }\end{array}$ & $\boldsymbol{p} \ddagger$ \\
\hline Visual search latency, ms & 324 & .02 & $\begin{array}{l}439.3 \\
(64.9)\end{array}$ & $\begin{array}{l}435.9 \\
(66.2)\end{array}$ & $\begin{array}{l}433.6 \\
(59.8)\end{array}$ & .99 \\
\hline $\begin{array}{l}\text { Visual search task, \% of } \\
\text { successful search, } \\
\text { conjunction }\end{array}$ & 340 & .00 & $\begin{array}{c}47.5 \\
(18.6)\end{array}$ & $\begin{array}{c}43.9 \\
(20.3)\end{array}$ & $\begin{array}{c}45.7 \\
(20.1)\end{array}$ & .53 \\
\hline $\begin{array}{l}\text { Anticipatory attention shifts } \\
\text { task, \% of correct } \\
\text { anticipation, post-switch }\end{array}$ & 365 & -.02 & $\begin{array}{c}59.1 \\
(29.0)\end{array}$ & $\begin{array}{l}52.1 \\
(27.9)\end{array}$ & $\begin{array}{c}54.0 \\
(28.4)\end{array}$ & .32 \\
\hline $\begin{array}{l}\text { Attention to faces task, } \\
\text { dwell time index on faces }\end{array}$ & 312 & .00 & $\begin{array}{c}.53 \\
(.20)\end{array}$ & $\begin{array}{c}.57 \\
(.20)\end{array}$ & $\begin{array}{c}.54 \\
(.20)\end{array}$ & .43 \\
\hline \multicolumn{7}{|c|}{$\begin{array}{l}\dagger \text { Values from Spearman’s rank correlation for visual search latency, Spearman’s partial rank } \\
\text { correlation for visual search task (adjusted to one-object and multiple-objects), anticipatory } \\
\text { attention shifts task (adjusted to pre-switch), and dwell time index on faces (adjusted to dwell } \\
\text { time index on control stimulus). } \\
\ddagger P \text { value from Kruskall-Wallis equality-of-populations rank test for comparison between GA } \\
\text { subgroups. }\end{array}$} \\
\hline
\end{tabular}


Table 6. Eye tracking results at 9 months of age by length-for-age z-score (LAZ) and weightfor-age z-score (WAZ)

Correlation coefficient between the indicated test variable and the below variables $\dagger$

\begin{tabular}{lccccc} 
Test variable & $\boldsymbol{N}$ & $\begin{array}{c}\text { LAZ at } \\
\text { enrollment }\end{array}$ & $\begin{array}{c}\text { LAZ at 9 } \\
\text { months } \ddagger\end{array}$ & $\begin{array}{c}\text { WAZ at } \\
\text { enrollment }\end{array}$ & $\begin{array}{c}\text { WAZ at 9 } \\
\text { months } \ddagger\end{array}$ \\
\hline Visual search latency & 324 & -.01 & .01 & .00 & .08 \\
$\begin{array}{l}\text { Visual search task, \% of } \\
\text { successful search, }\end{array}$ & 340 & .04 & .12 & .09 & .14 \\
$\begin{array}{l}\text { conjunction } \\
\begin{array}{l}\text { Anticipatory attention } \\
\text { shifts task, \% of correct }\end{array}\end{array}$ & 365 & .12 & -.11 & .11 & -.17 \\
$\begin{array}{l}\text { anticipation, post-switch } \\
\begin{array}{l}\text { Attention to faces task, } \\
\text { dwell time index on faces }\end{array}\end{array}$ & 312 & & & & \\
\hline
\end{tabular}

$\dagger$ Values from Spearman's partial rank correlation as all values are adjusted to gestational age at birth. Additional adjustments in following variables: visual search task (adjusted to oneobject and multiple-objects), anticipatory attention shifts task (adjusted to pre-switch), and dwell time index on faces (adjusted to dwell time index on control stimulus). $\ddagger$ Adjusted to LAZ or WAZ at enrollment. 
Table 7. Eye tracking results at 9 months of age by maternal characteristics

\begin{tabular}{|c|c|c|c|c|c|}
\hline \multirow[b]{2}{*}{ Test variable } & \multirow[b]{2}{*}{$N$} & \multicolumn{4}{|c|}{$\begin{array}{c}\text { Correlation coefficient between the indicated test variable and } \\
\text { the below continuous variables } \dagger\end{array}$} \\
\hline & & Cognition & $\begin{array}{l}\text { Psychosocial } \\
\text { Well-being }\end{array}$ & $\begin{array}{l}\text { Socioeconomic } \\
\text { Status }\end{array}$ & $\begin{array}{c}\text { Care } \\
\text { Practices }\end{array}$ \\
\hline Visual search latency & 324 & -.05 & .06 & .06 & .00 \\
\hline $\begin{array}{l}\text { Visual search task, \% of } \\
\text { successful search, conjunction }\end{array}$ & 340 & .11 & .01 & .08 & .14 \\
\hline $\begin{array}{l}\text { Anticipatory attention shifts } \\
\text { task, \% of correct anticipation, } \\
\text { post-switch }\end{array}$ & 365 & .04 & -.06 & .07 & .04 \\
\hline $\begin{array}{l}\text { Attention to faces task, dwell } \\
\text { time index on faces }\end{array}$ & 312 & -.06 & -.12 & -.09 & .00 \\
\hline
\end{tabular}

† Values from Spearman's rank correlation for visual search latency, and from Spearman's partial rank correlation for visual search task (adjusted to one-object and multiple-objects), anticipatory attention shifts task (adjusted to pre-switch), and dwell time index on faces (adjusted to dwell time index on control stimulus). 


\section{Supplementary material}

Table S1. Time points of data collection

\begin{tabular}{|l|l|l|l|l|l|}
\hline Visit & $\begin{array}{c}\text { Clinic visit } \\
\text { (Enrollment) }\end{array}$ & Home visit & Home visit & \multicolumn{1}{c|}{$\begin{array}{c}\text { Clinic visit } \\
\text { (7 months) }\end{array}$} & $\begin{array}{c}\text { Clinic visit } \\
\text { (9 months) }\end{array}$ \\
\hline $\begin{array}{l}\text { Time } \\
\text { point } \\
\text { from } \\
\text { birth }\end{array}$ & $\mathbf{0 - 4}$ weeks & $\mathbf{1 5}$ weeks & $\mathbf{2 9}$ weeks & $\mathbf{3 0}$ weeks & $\mathbf{3 9}$ weeks \\
\hline $\begin{array}{l}\text { Data } \\
\text { collected }\end{array}$ & $\begin{array}{l}\text { Screening, } \\
\text { approval, } \\
\text { consent, and } \\
\text { enrollment }\end{array}$ & $\begin{array}{l}\text { Maternal } \\
\text { cognition }\end{array}$ & $\begin{array}{l}\text { Social and } \\
\text { demographic } \\
\text { environment }\end{array}$ & $\begin{array}{l}\text { Anthropometrics, } \\
\text { medical, motor } \\
\text { milestones }\end{array}$ & $\begin{array}{l}\text { Anthropometrics, } \\
\text { medical, motor } \\
\text { milestones }\end{array}$ \\
\cline { 2 - 6 } & \begin{tabular}{l} 
Anthropometrics \\
\cline { 2 - 6 }
\end{tabular} & & $\begin{array}{l}\text { HOME } \\
\text { sood }\end{array}$ & $\begin{array}{l}\text { Eye tracking } \\
\text { structured } \\
\text { observations }\end{array}$ & $\begin{array}{l}\text { Eye tracking } \\
\text { observations }\end{array}$ \\
\cline { 2 - 6 } & & $\begin{array}{l}\text { Maternal } \\
\text { social } \\
\text { support }\end{array}$ & $\begin{array}{l}\text { Maternal SRQ } \\
\text { depression }\end{array}$ & $\begin{array}{l}\text { Maternal } \\
\text { perceived stress }\end{array}$ \\
\cline { 2 - 6 } & & $\begin{array}{l}\text { Mother-infant } \\
\text { bond }\end{array}$ & $\begin{array}{l}\text { Maternal life } \\
\text { events }\end{array}$ \\
\hline
\end{tabular}

Figure S1. A practice item of the mental rotation of the maternal cognition test. The mother was asked to point out the rotated figures (white) of the original figure (grey).

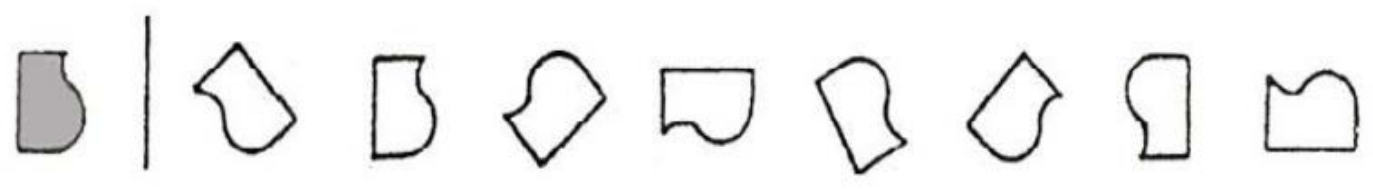


Table S2. Maternal characteristics scores prior to standardization (higher score indicates positive outcome)

\begin{tabular}{|c|c|c|c|}
\hline Test variable & $N$ & Mean (SD) & Range \\
\hline \multicolumn{4}{|l|}{ Cognition } \\
\hline Mental rotation test & 429 & $24.9(4.8)$ & $13-40$ \\
\hline Digit span test, forward & 429 & $5.2(1.5)$ & $2-10$ \\
\hline Digit span test, backward & 429 & $2.4(1.5)$ & $0-8$ \\
\hline Verbal fluency test, foods & 429 & $15.3(4.8)$ & $4-31$ \\
\hline Verbal fluency test, girls’ names & 429 & $16.3(5.2)$ & 3-31 \\
\hline \multicolumn{4}{|l|}{ Psychosocial well-being } \\
\hline Depression symptoms & 419 & $14.2(4.1)$ & $2-20$ \\
\hline Perceived stress & 409 & $21.9(4.1)$ & $9-32$ \\
\hline Adverse life events & 409 & $29.4(2.9)$ & $20-34$ \\
\hline Social support & 424 & $34.0(7.5)$ & $12-48$ \\
\hline \multicolumn{4}{|l|}{ Socioeconomic status } \\
\hline Satisfaction of everyday needs & 424 & $5.1(1.6)$ & $0-9$ \\
\hline Food insecurity & 424 & $18.5(5.4)$ & $3-27$ \\
\hline Living conditions & 444 & $13.1(1.9)$ & $7-21$ \\
\hline \multicolumn{4}{|l|}{ Care practices } \\
\hline Mother-infant bond & 419 & $18.9(2.4)$ & $11-24$ \\
\hline HOME observation & 424 & $23.8(2.4)$ & $13-30$ \\
\hline
\end{tabular}


Table S3. Odd-even split-half Spearman's rank correlation coefficients for eye tracking results with different number of valid trials

\begin{tabular}{|c|c|c|c|c|c|c|c|}
\hline \multirow[b]{2}{*}{ Test variable } & \multirow[b]{2}{*}{$\begin{array}{l}\mathbf{N} \text { of valid trials } \\
\text { per condition } \dagger\end{array}$} & \multicolumn{3}{|c|}{$\begin{array}{l}\text { Odd-even split-half tests } \\
\text { (at } 7 \text { months of age) }\end{array}$} & \multicolumn{3}{|c|}{$\begin{array}{l}\text { Odd-even split-half tests } \\
\text { (at } 9 \text { months of age) }\end{array}$} \\
\hline & & $\begin{array}{c}\mathrm{N} \text { of } \\
\text { participants }\end{array}$ & $\begin{array}{l}\text { Spearman's } \\
\text { rho }\end{array}$ & $\boldsymbol{P}$ & $\begin{array}{c}\mathrm{N} \text { of } \\
\text { participants }\end{array}$ & $\begin{array}{l}\text { Spearman's } \\
\text { rho }\end{array}$ & $\boldsymbol{P}$ \\
\hline \multirow{4}{*}{ Visual search latency } & $\geq 1$ & 380 & 0.26 & $<0.01$ & 363 & 0.18 & $<0.01$ \\
\hline & $\geq 2$ & 311 & 0.35 & $<0.01$ & 300 & 0.22 & $<0.01$ \\
\hline & $\geq 3$ & 198 & 0.42 & $<0.01$ & 210 & 0.38 & $<0.01$ \\
\hline & $\geq 4$ & 93 & 0.28 & $<0.01$ & 96 & 0.48 & $<0.01$ \\
\hline \multirow{4}{*}{$\begin{array}{l}\text { Visual search task, \% of } \\
\text { successful search, } \\
\text { conjunction }\end{array}$} & $\geq 1$ & 382 & -0.03 & 0.53 & 368 & -0.01 & 0.85 \\
\hline & $\geq 2$ & 319 & -0.06 & 0.25 & 316 & -0.02 & 0.71 \\
\hline & $\geq 3$ & 218 & -0.06 & 0.40 & 215 & -0.09 & 0.17 \\
\hline & $\geq 4$ & 88 & -0.08 & 0.45 & 93 & 0.03 & 0.74 \\
\hline \multirow{8}{*}{$\begin{array}{l}\text { Anticipatory attention } \\
\text { shifts task, \% of correct } \\
\text { anticipation, post- } \\
\text { switch }\end{array}$} & $\geq 1$ & 389 & 0.64 & $<0.01$ & 383 & 0.60 & $<0.01$ \\
\hline & $\geq 2$ & 368 & 0.66 & $<0.01$ & 360 & 0.62 & $<0.01$ \\
\hline & $\geq 3$ & 325 & 0.69 & $<0.01$ & 342 & 0.63 & $<0.01$ \\
\hline & $\geq 4$ & 264 & 0.69 & $<0.01$ & 295 & 0.65 & $<0.01$ \\
\hline & $\geq 5$ & 207 & 0.74 & $<0.01$ & 252 & 0.69 & $<0.01$ \\
\hline & $\geq 6$ & 128 & 0.70 & $<0.01$ & 191 & 0.69 & $<0.01$ \\
\hline & $\geq 7$ & 60 & 0.68 & $<0.01$ & 96 & 0.67 & $<0.01$ \\
\hline & $\geq 8$ & 19 & 0.87 & $<0.01$ & 29 & 0.73 & $<0.01$ \\
\hline \multirow{8}{*}{$\begin{array}{l}\text { Attention to faces task, } \\
\text { dwell time index on } \\
\text { faces }\end{array}$} & $\geq 1$ & 385 & 0.56 & $<0.01$ & 378 & 0.54 & $<0.01$ \\
\hline & $\geq 2$ & 359 & 0.62 & $<0.01$ & 360 & 0.55 & $<0.01$ \\
\hline & $\geq 3$ & 322 & 0.65 & $<0.01$ & 334 & 0.56 & $<0.01$ \\
\hline & $\geq 4$ & 291 & 0.66 & $<0.01$ & 312 & 0.57 & $<0.01$ \\
\hline & $\geq 5$ & 250 & 0.68 & $<0.01$ & 268 & 0.55 & $<0.01$ \\
\hline & $\geq 6$ & 194 & 0.72 & $<0.01$ & 232 & 0.55 & $<0.01$ \\
\hline & $\geq 7$ & 117 & 0.76 & $<0.01$ & 166 & 0.55 & $<0.01$ \\
\hline & $\geq 8$ & 39 & 0.74 & $<0.01$ & 83 & 0.60 & $<0.01$ \\
\hline
\end{tabular}

$\uparrow \mathrm{N}$ or more trials for both even and odd trials per participant needed for each variable. 
Table S4. Test-retest Spearman's rank correlation coefficients for eye tracking results with different number of valid trials

\begin{tabular}{lcccc}
\hline & & \multicolumn{2}{c}{ Test-retest (7 v 9 months of age) } \\
\cline { 3 - 5 } Test variable & $\begin{array}{c}\text { N of valid trials per } \\
\text { condition }\end{array}$ & $\begin{array}{c}\text { N of } \\
\text { participants }\end{array}$ & Spearman's rho & P \\
\hline Visual search latency & $\geq 3$ & 273 & 0.28 & $<0.01$ \\
& $\geq 4$ & 228 & 0.36 & $<0.01$ \\
& $\geq 5$ & 169 & 0.35 & $<0.01$ \\
& $\geq 6$ & 95 & 0.35 & $<0.01$ \\
& $\geq 7$ & 44 & 0.37 & 0.01 \\
& $\geq 8$ & 7 & 0.54 & 0.21 \\
\hline Visual search task, \% & $\geq 3$ & 294 & 0.20 & $<0.01$ \\
of successful search, & $\geq 4$ & 237 & 0.22 & $<0.01$ \\
conjunction & $\geq 5$ & 172 & 0.24 & $<0.01$ \\
& $\geq 6$ & 95 & 0.24 & 0.02 \\
& $\geq 7$ & 44 & 0.29 & 0.05 \\
& $\geq 8$ & 7 & 0.09 & 0.85 \\
\hline Anticipatory attention & $\geq 3$ & 338 & 0.07 & 0.22 \\
shifts task, \% of correct & $\geq 4$ & 317 & 0.07 & 0.23 \\
anticipation, post- & $\geq 5$ & 295 & 0.07 & 0.23 \\
switch & $\geq 6$ & 278 & 0.06 & 0.33 \\
& $\geq 7$ & 248 & 0.07 & 0.23 \\
& $\geq 8$ & 312 & 0.05 & 0.51 \\
\hline Attention to faces task, & $\geq 3$ & 255 & 0.44 & $<0.01$ \\
dwell time index on & $\geq 4$ & 198 & 0.45 & $<0.01$ \\
faces & $\geq 5$ & 96 & 0.46 & $<0.01$ \\
& $\geq 8$ & 40 & 0.53 & $<0.01$ \\
& $\geq 8$ & 0.51 & $<0.01$ \\
& & & 0.86 & 0.01 \\
\hline
\end{tabular}


Table S5. Eye tracking results at 7 months of age by gestational age at birth (GA)

Mean (SD) for the indicated test variable in participant subgroups

\begin{tabular}{|c|c|c|c|c|c|c|}
\hline Test variable & $N$ & $\begin{array}{c}\text { Correlation } \\
\text { coefficient } \\
\text { between the } \\
\text { indicated } \\
\text { test variable } \\
\text { and GA } \dagger\end{array}$ & $\begin{array}{l}\text { Infants } \\
\text { born } \\
\text { preterm }\end{array}$ & $\begin{array}{l}\text { Infants } \\
\text { born early } \\
\text { term }\end{array}$ & $\begin{array}{l}\text { Infants born } \\
\text { full term }\end{array}$ & $p \neq$ \\
\hline Visual search latency, ms & 337 & -0.03 & $\begin{array}{l}446.3 \\
(66.7)\end{array}$ & $\begin{array}{l}452.3 \\
(74.5)\end{array}$ & $\begin{array}{l}446.0 \\
(66.3)\end{array}$ & .84 \\
\hline $\begin{array}{l}\text { Visual search task, \% of } \\
\text { successful search, conjunction }\end{array}$ & 349 & -0.06 & $\begin{array}{c}46.3 \\
(20.9)\end{array}$ & $\begin{array}{c}45.0 \\
(19.8)\end{array}$ & $\begin{array}{c}42.5 \\
(19.7)\end{array}$ & .37 \\
\hline $\begin{array}{l}\text { Anticipatory attention shifts } \\
\text { task, \% of correct anticipation, } \\
\text { post-switch }\end{array}$ & 376 & 0.01 & $\begin{array}{c}46.0 \\
(28.7)\end{array}$ & $\begin{array}{c}47.0 \\
(29.3)\end{array}$ & $\begin{array}{l}45.7 \\
(28.9)\end{array}$ & .93 \\
\hline $\begin{array}{l}\text { Attention to faces task, dwell } \\
\text { time index on faces }\end{array}$ & 312 & 0.05 & $\begin{array}{l}.58 \\
(.22)\end{array}$ & $\begin{array}{l}.57 \\
(.21)\end{array}$ & $\begin{array}{c}.58 \\
(.23)\end{array}$ & .99 \\
\hline
\end{tabular}

$\dagger$ Values from Spearman's rank correlation for visual search latency, Spearman's partial rank correlation for visual search task (adjusted to one-object and multiple-objects), anticipatory attention shifts task (adjusted to pre-switch), and dwell time index on faces (adjusted to dwell time index on control stimulus).

$\ddagger P$ value from Kruskall-Wallis equality-of-populations rank test for comparison between GA subgroups. 
Table S6. Eye tracking results at 7 months of age by length-for-age z-score (LAZ) and weight-for-age z-score (WAZ)

Correlation coefficient between the indicated test variable and the below continuous variables $\dagger$

\begin{tabular}{lccccc} 
Test variable & $\boldsymbol{N}$ & $\begin{array}{c}\text { LAZ at } \\
\text { enrollment }\end{array}$ & $\begin{array}{c}\text { LAZ at } 7 \\
\text { months } \ddagger\end{array}$ & $\begin{array}{c}\text { WAZ at } \\
\text { enrollment }\end{array}$ & $\begin{array}{c}\text { WAZ at 7 } \\
\text { months } \S\end{array}$ \\
\hline $\begin{array}{l}\text { Visual search latency } \\
\text { Visual search task, \% of }\end{array}$ & 337 & 0.09 & -0.11 & 0.00 & -0.11 \\
$\begin{array}{l}\text { successful search, } \\
\text { conjunction }\end{array}$ & 349 & 0.10 & 0.02 & 0.00 & -0.04 \\
$\begin{array}{l}\text { Anticipatory attention } \\
\text { shifts task, \% of correct } \\
\text { anticipation, post-switch }\end{array}$ & 376 & 0.01 & -0.13 & -0.02 & -0.12 \\
$\begin{array}{l}\text { Attention to faces task, } \\
\text { dwell time index on faces }\end{array}$ & 312 & -0.04 & & & \\
\hline
\end{tabular}

$\dagger$ Values from Spearman's partial rank correlation as all values are adjusted to gestational age at birth. Additional adjustments in following variables: visual search task (adjusted to oneobject and multiple-objects), anticipatory attention shifts task (adjusted to pre-switch), and dwell time index on faces (adjusted to dwell time index on control stimulus).

$\ddagger$ Adjusted to LAZ at enrollment.

$\S$ Adjusted to WAZ at enrollment 
Table S7. Eye tracking results at 7 months of age by maternal characteristics.

Correlation coefficient between the indicated test variable and the below continuous variables $\dagger$

\begin{tabular}{|c|c|c|c|c|c|}
\hline Test variable & $N$ & Cognition & $\begin{array}{c}\text { Psychosocial } \\
\text { Well-being }\end{array}$ & $\begin{array}{l}\text { Socioeconomic } \\
\text { Status }\end{array}$ & $\begin{array}{c}\text { Care } \\
\text { Practices }\end{array}$ \\
\hline Visual search latency & 337 & -0.02 & $\begin{array}{c}0.04 \\
\left(N=331^{\ddagger}\right)\end{array}$ & 0.03 & 0.09 \\
\hline $\begin{array}{l}\text { Visual search task, \% of } \\
\text { successful search, } \\
\text { conjunction }\end{array}$ & 349 & 0.04 & $\begin{array}{c}0.05 \\
\left(N=343^{\ddagger}\right)\end{array}$ & 0.07 & 0.03 \\
\hline $\begin{array}{l}\text { Anticipatory attention } \\
\text { shifts task, \% of correct } \\
\text { anticipation, post-switch }\end{array}$ & 376 & -0.05 & $\begin{array}{c}-0.03 \\
\left(N=370^{\ddagger}\right)\end{array}$ & -0.11 & -0.02 \\
\hline $\begin{array}{l}\text { Attention to faces task, } \\
\text { dwell time index on } \\
\text { faces }\end{array}$ & 312 & 0.01 & $\begin{array}{c}-0.08 \\
\left(N=306^{\ddagger}\right)\end{array}$ & -0.04 & -0.03 \\
\hline
\end{tabular}

† Values from Spearman's rank correlation for visual search latency, and from Spearman's partial rank correlation for visual search task (adjusted to one-object and multiple-objects), anticipatory attention shifts task (adjusted to pre-switch), and dwell time index on faces (adjusted to dwell time index on control stimulus).

$\ddagger$ Data not collected for 6 mothers as they dropped out before the scheduled data collection at 9 months. 
Table S8. Eye tracking results at 7 and 9 months of age by anthropometrics measurements for length-for-age z-score (LAZ), weight-for-length z-score (WLZ), head circumference-for-age z-score (HCZ), mid-upper arm circumference (MUAC), and changes between indicated time points and enrollment $(\Delta)$ (adjusted to gestational age at birth).

\begin{tabular}{|c|c|c|c|c|c|c|c|c|c|c|c|c|c|c|c|}
\hline \multirow[b]{2}{*}{ Test variable } & \multirow[b]{2}{*}{$\begin{array}{l}\text { Time } \\
\text { point }\end{array}$} & \multirow[b]{2}{*}{$N$} & \multicolumn{13}{|c|}{ Correlation coefficient between the indicated test variable and the below continuous variables $\dagger$} \\
\hline & & & $\begin{array}{c}\text { MUAC } \\
\text { enrollment }\end{array}$ & $\begin{array}{c}\text { MUAC } \\
7 / 9 \mathrm{mo}\end{array}$ & $\begin{array}{c}\text { MUAC } \\
\Delta\end{array}$ & $\begin{array}{c}\text { WLZ } \\
\text { enrollment } \\
\ddagger\end{array}$ & $\begin{array}{c}\text { WLZ } \\
\text { 7/9 mo } \\
\ddagger\end{array}$ & $\begin{array}{c}\text { WLZ } \\
\Delta \neq\end{array}$ & $\begin{array}{c}\text { HCZ } \\
\text { enrollment }\end{array}$ & $\begin{array}{c}\text { HCZ } \\
\text { 7/9 mo }\end{array}$ & $\begin{array}{c}\mathrm{HCZ} \\
\Delta\end{array}$ & $\begin{array}{c}\text { LAZ } \\
\Delta\end{array}$ & $\begin{array}{c}\text { WAZ } \\
\Delta\end{array}$ & $\begin{array}{c}\text { LAZ } \\
\Delta \\
\text { from } \\
7 \text { to } \\
9 \text { mo } \\
\S\end{array}$ & $\begin{array}{c}\text { WAZ } \\
\Delta \\
\text { from } \\
7 \text { to } 9 \\
\text { mo } \S\end{array}$ \\
\hline \multirow[b]{2}{*}{ Visual search latency } & $7 \mathrm{mo}$ & 337 & 0.01 & -0.13 & -0.13 & -0.10 & -0.06 & -0.06 & 0.06 & -0.13 & -0.09 & -0.10 & -0.11 & $N / A$ & $N / A$ \\
\hline & 9 mo & 324 & 0.00 & 0.09 & 0.10 & 0.04 & 0.07 & 0.09 & 0.06 & 0.11 & 0.10 & 0.00 & 0.09 & $\begin{array}{l}0.02 \\
(N= \\
319)\end{array}$ & $\begin{array}{l}0.09 \\
(N= \\
319)\end{array}$ \\
\hline \multirow[b]{2}{*}{$\begin{array}{l}\text { Visual search task, \% } \\
\text { of successful search, } \\
\text { conjunction }\end{array}$} & $7 \mathrm{mo}$ & 349 & 0.01 & -0.04 & 0.01 & -0.15 & -0.08 & -0.06 & -0.02 & -0.12 & -0.08 & 0.01 & -0.03 & $N / A$ & $N / A$ \\
\hline & 9 mo & 340 & 0.11 & 0.10 & 0.10 & 0.07 & 0.13 & 0.10 & 0.04 & 0.04 & 0.04 & 0.09 & 0.13 & $\begin{array}{l}0.15 \\
(N= \\
335)\end{array}$ & $\begin{array}{l}0.14 \\
(N= \\
335)\end{array}$ \\
\hline \multirow{2}{*}{$\begin{array}{l}\text { Anticipatory attention } \\
\text { shifts task, \% of } \\
\text { correct anticipation, } \\
\text { post-switch }\end{array}$} & $7 \mathrm{mo}$ & 376 & 0.01 & -0.12 & -0.11 & -0.05 & -0.05 & -0.04 & -0.03 & -0.10 & -0.05 & -0.12 & -0.12 & N/A & $N / A$ \\
\hline & $9 \mathrm{mo}$ & 365 & 0.14 & -0.14 & -0.15 & 0.04 & -0.14 & -0.12 & 0.08 & -0.02 & -0.06 & -0.09 & -0.15 & $\begin{array}{l}-0.07 \\
(N= \\
360)\end{array}$ & $\begin{array}{l}-0.04 \\
(N= \\
360)\end{array}$ \\
\hline \multirow[b]{2}{*}{$\begin{array}{l}\text { Attention to faces } \\
\text { task, dwell time index } \\
\text { on faces }\end{array}$} & $7 \mathrm{mo}$ & 312 & 0.01 & -0.04 & -0.01 & -0.03 & -0.08 & -0.09 & -0.08 & -0.08 & -0.09 & -0.01 & -0.05 & $N / A$ & $N / A$ \\
\hline & 9 mo & 312 & -0.01 & -0.03 & -0.04 & -0.02 & -0.02 & -0.04 & 0.05 & -0.01 & -0.01 & 0.01 & -0.02 & $\begin{array}{l}0.13 \\
(N= \\
308)\end{array}$ & $\begin{array}{l}-0.03 \\
(N= \\
308)\end{array}$ \\
\hline
\end{tabular}

† Values from Spearman's rank correlation for visual search latency, and from Spearman's partial rank correlation for visual search task (adjusted to one-object and multipleobjects), anticipatory attention shifts task (adjusted to pre-switch), and dwell time index on faces (adjusted to dwell time index on control stimulus). Values adjusted to gestational age at birth.

$\ddagger \mathrm{N}$ for WLZ measurements at $7 \mathrm{mo}=297,307,334,274$, and 274, and at 9 mo $=287,301,324,276$, and 276, for Visual search latency, Visual search task, Anticipatory attention shifts task, Attention to faces task, and Dwell time index on faces, respectively, due to length out of reference charts at enrollment ( $<45 \mathrm{~cm})$.

$\S$ Adjusted to LAZ or WAZ at 7 months of age. 
Table S9. Eye tracking results at 7 and 9 months of age with imputed enrollment length measurements for length-for-age z-score (LAZ), weight-for-length z-score (WLZ), and changes between indicated time points and enrollment ( $\Delta$ ) (adjusted to gestational age at birth). $\dagger$

\begin{tabular}{|c|c|c|c|c|c|c|c|c|}
\hline \multirow[b]{2}{*}{ Test variable } & \multirow[b]{2}{*}{$\begin{array}{l}\text { Time } \\
\text { point }\end{array}$} & \multirow[b]{2}{*}{$\begin{array}{c}N \\
\text { LAZ/WLZ }\end{array}$} & \multicolumn{6}{|c|}{ Correlation coefficient between the indicated test variable and the below continuous variables $\ddagger$} \\
\hline & & & LAZ enrollment & $\begin{array}{c}\text { LAZ 7/9 mo } \\
\S\end{array}$ & $\mathbf{L A Z} \Delta \S$ & $\begin{array}{c}\text { WLZ } \\
\text { enrollment }\end{array}$ & WLZ 7/9 mo $\S$ & WLZ $\Delta \S$ \\
\hline \multirow{2}{*}{$\begin{array}{l}\text { Visual search } \\
\text { latency }\end{array}$} & $7 \mathrm{mo}$ & $337 / 317$ & .05 & -.11 & -.11 & -.05 & -.08 & -.05 \\
\hline & 9 mo & $324 / 304$ & -.01 & .01 & -.01 & .03 & .08 & .10 \\
\hline \multirow{2}{*}{$\begin{array}{l}\text { Visual search task, } \\
\% \text { of successful } \\
\text { search, conjunction }\end{array}$} & $7 \mathrm{mo}$ & $349 / 327$ & .11 & .00 & .02 & -.17 & -.07 & -.06 \\
\hline & $9 \mathrm{mo}$ & $340 / 319$ & .04 & .13 & .13 & .06 & .13 & .12 \\
\hline \multirow{2}{*}{$\begin{array}{l}\text { Anticipatory } \\
\text { attention shifts task, } \\
\% \text { of correct } \\
\text { anticipation, post- } \\
\text { switch }\end{array}$} & $7 \mathrm{mo}$ & $376 / 353$ & -.04 & -.11 & -.09 & .00 & -.06 & -.09 \\
\hline & $9 \mathrm{mo}$ & $365 / 344$ & .10 & -.13 & -.14 & .05 & -.14 & -.13 \\
\hline $\begin{array}{l}\text { Attention to faces } \\
\text { task, dwell time }\end{array}$ & $7 \mathrm{mo}$ & $312 / 293$ & -.04 & -.02 & .00 & -.07 & -.08 & -.08 \\
\hline index on faces & $9 \mathrm{mo}$ & $312 / 293$ & .04 & .00 & .02 & -.05 & -.03 & -.04 \\
\hline
\end{tabular}

† LAZ 0 mo (enrollment) imputed for children collected by two collectors in Malindi. Single linear regression model (Length at enrollment $\sim$ Gender + Age at enrollment + Weight at enrollment + MUAC at enrollment + Head circumference at enrollment + WAZ at 7 mo + LAZ at 7 mo + HCZ at 7 mo + MUACZ at 7 mo) based on non-imputed cases.

¥ Values from Spearman’s rank correlation for visual search latency, and from Spearman’s partial rank correlation for visual search task (adjusted to one-object and multipleobjects), anticipatory attention shifts task (adjusted to pre-switch), and dwell time index on faces (adjusted to dwell time index on control stimulus). Values adjusted to gestational age at birth.

$\S$ Adjusted to enrollment LAZ or WAZ at enrollment 
Table S10. Eye tracking results at 9 months of age with different number of valid trials per condition for child's anthropometrics. $\dagger$

\begin{tabular}{|c|c|c|c|c|c|c|c|c|c|c|c|c|}
\hline \multirow[b]{2}{*}{ Test variable } & \multirow[b]{2}{*}{$\begin{array}{l}N \text { of valid trials } \\
\text { per condition }\end{array}$} & \multirow[b]{2}{*}{$\begin{array}{c}N \text { of } \\
\text { participants }\end{array}$} & \multicolumn{2}{|l|}{ GA } & \multicolumn{2}{|c|}{ LAZ at enrollment } & \multicolumn{2}{|c|}{$\begin{array}{c}\text { LAZ at } 9 \text { months of } \\
\text { age }\end{array}$} & \multicolumn{2}{|c|}{ WAZ at enrollment } & \multicolumn{2}{|c|}{$\begin{array}{c}\text { WAZ at } 9 \text { months of } \\
\text { age }\end{array}$} \\
\hline & & & $\begin{array}{l}\text { Spearman's } \\
\text { rho }\end{array}$ & $\boldsymbol{P}$ & $\begin{array}{l}\text { Spearman's } \\
\text { rho }\end{array}$ & $\boldsymbol{P}$ & $\begin{array}{l}\text { Spearman's } \\
\text { rho }\end{array}$ & $\boldsymbol{P}$ & $\begin{array}{l}\text { Spearman's } \\
\text { rho }\end{array}$ & $P$ & $\begin{array}{l}\text { Spearman's } \\
\text { rho }\end{array}$ & $P$ \\
\hline \multirow{6}{*}{$\begin{array}{l}\text { Visual search } \\
\text { latency }\end{array}$} & $\geq 3$ & 324 & 0.02 & 0.74 & -0.01 & 0.79 & 0.01 & 0.83 & 0.00 & 0.97 & 0.08 & 0.16 \\
\hline & $\geq 4$ & 293 & 0.03 & 0.57 & -0.02 & 0.77 & 0.00 & 0.99 & 0.00 & 0.96 & 0.08 & 0.17 \\
\hline & $\geq 5$ & 254 & 0.02 & 0.72 & -0.04 & 0.48 & 0.00 & 0.96 & -0.03 & 0.58 & 0.10 & 0.12 \\
\hline & $\geq 6$ & 202 & 0.04 & 0.55 & -0.04 & 0.54 & -0.03 & 0.67 & -0.04 & 0.59 & 0.07 & 0.30 \\
\hline & $\geq 7$ & 121 & 0.06 & 0.50 & 0.03 & 0.71 & 0.01 & 0.91 & -0.02 & 0.82 & 0.09 & 0.34 \\
\hline & $\geq 8$ & 37 & 0.11 & 0.53 & -0.08 & 0.70 & -0.01 & 0.97 & -0.17 & 0.33 & 0.04 & 0.84 \\
\hline \multirow{6}{*}{$\begin{array}{l}\text { Visual search } \\
\text { task, \% of } \\
\text { successful } \\
\text { search, } \\
\text { conjunction }\end{array}$} & $\geq 3$ & 340 & 0.00 & 0.99 & 0.04 & 0.44 & 0.12 & 0.03 & 0.09 & 0.08 & 0.14 & 0.01 \\
\hline & $\geq 4$ & 304 & 0.02 & 0.71 & 0.06 & 0.28 & 0.10 & 0.07 & 0.12 & 0.03 & 0.12 & 0.04 \\
\hline & $\geq 5$ & 258 & 0.01 & 0.86 & 0.11 & 0.08 & 0.07 & 0.28 & 0.15 & 0.02 & 0.10 & 0.10 \\
\hline & $\geq 6$ & 203 & 0.04 & 0.62 & 0.12 & 0.09 & 0.07 & 0.36 & 0.18 & 0.01 & 0.13 & 0.07 \\
\hline & $\geq 7$ & 121 & 0.00 & 0.97 & 0.08 & 0.42 & 0.14 & 0.14 & 0.17 & 0.06 & 0.19 & 0.04 \\
\hline & $\geq 8$ & 37 & -0.18 & 0.31 & 0.30 & 0.08 & 0.39 & 0.03 & 0.45 & 0.01 & 0.38 & 0.03 \\
\hline \multirow{6}{*}{$\begin{array}{l}\text { Anticipatory } \\
\text { attention } \\
\text { shifts task, \% } \\
\text { of correct } \\
\text { anticipation, } \\
\text { post-switch }\end{array}$} & $\geq 3$ & 365 & -0.02 & 0.67 & 0.12 & 0.03 & -0.11 & 0.03 & 0.11 & 0.04 & -0.17 & $<0.01$ \\
\hline & $\geq 4$ & 355 & -0.02 & 0.67 & 0.11 & 0.05 & -0.11 & 0.05 & 0.11 & 0.04 & -0.18 & $<0.01$ \\
\hline & $\geq 5$ & 338 & 0.00 & 0.98 & 0.11 & 0.05 & -0.10 & 0.07 & 0.10 & 0.06 & -0.17 & $<0.01$ \\
\hline & $\geq 6$ & 330 & 0.02 & 0.73 & 0.10 & 0.08 & -0.11 & 0.04 & 0.08 & 0.15 & -0.17 & $<0.01$ \\
\hline & $\geq 7$ & 315 & 0.00 & 0.97 & 0.11 & 0.05 & -0.12 & 0.04 & 0.09 & 0.10 & -0.18 & $<0.01$ \\
\hline & $\geq 8$ & 295 & 0.00 & 0.94 & 0.11 & 0.07 & -0.13 & 0.03 & 0.10 & 0.09 & -0.20 & $<0.01$ \\
\hline \multirow{6}{*}{$\begin{array}{l}\text { Attention to } \\
\text { faces task, } \\
\text { dwell time } \\
\text { index on } \\
\text { faces }\end{array}$} & $\geq 3$ & 312 & 0.00 & 0.98 & 0.04 & 0.52 & 0.02 & 0.74 & 0.01 & 0.84 & -0.01 & 0.82 \\
\hline & $\geq 4$ & 272 & 0.00 & 0.96 & 0.08 & 0.24 & 0.00 & 0.98 & 0.04 & 0.50 & -0.02 & 0.72 \\
\hline & $\geq 5$ & 221 & 0.03 & 0.71 & 0.01 & 0.87 & 0.00 & 0.99 & -0.04 & 0.51 & -0.03 & 0.63 \\
\hline & $\geq 6$ & 178 & 0.02 & 0.75 & -0.02 & 0.79 & 0.05 & 0.52 & -0.11 & 0.15 & 0.05 & 0.54 \\
\hline & $\geq 7$ & 109 & -0.04 & 0.72 & -0.04 & 0.70 & 0.11 & 0.28 & -0.03 & 0.73 & 0.03 & 0.79 \\
\hline & $\geq 8$ & 39 & 0.02 & 0.89 & -0.03 & 0.88 & 0.27 & 0.11 & -0.04 & 0.79 & 0.25 & 0.15 \\
\hline
\end{tabular}

† Values from Spearman’s rank correlation for visual search latency, Spearman’s partial rank correlation for visual search task (adjusted to one-object and multiple-objects), anticipatory

attention shifts task (adjusted to pre-switch), and dwell time index on faces (adjusted to dwell time index on control stimulus). LAZ (length-for-age z-score) and WAZ (weight-for-age z-score)

at enrollment adjusted to gestational age at birth (GA). LAZ and WAZ at 9 months of age adjusted to GA and LAZ or WAZ at enrollment, respectively. 
Table S11. Eye tracking results at 9 months of age with different number of valid trials per condition for maternal scores. $†$

\begin{tabular}{|c|c|c|c|c|c|c|c|c|c|c|}
\hline \multirow[b]{2}{*}{ Test variable } & \multirow[b]{2}{*}{$\begin{array}{l}N \text { of valid } \\
\text { trials per } \\
\text { condition }\end{array}$} & \multirow[b]{2}{*}{$\begin{array}{c}\mathrm{N} \text { of } \\
\text { participants }\end{array}$} & \multicolumn{2}{|c|}{ Cognition } & \multicolumn{2}{|c|}{ Psychosocial well-being } & \multicolumn{2}{|c|}{ Socioeconomic status } & \multicolumn{2}{|c|}{ Care practices } \\
\hline & & & $\begin{array}{c}\text { Spearman's } \\
\text { rho }\end{array}$ & $\boldsymbol{P}$ & $\begin{array}{c}\text { Spearman's } \\
\text { rho }\end{array}$ & $\boldsymbol{P}$ & $\begin{array}{c}\text { Spearman's } \\
\text { rho }\end{array}$ & $\boldsymbol{P}$ & $\begin{array}{c}\text { Spearman's } \\
\text { rho }\end{array}$ & $\boldsymbol{P}$ \\
\hline Visual search & $\geq 3$ & 324 & -0.05 & 0.42 & 0.06 & 0.27 & 0.06 & 0.30 & 0.00 & 0.99 \\
\hline \multirow[t]{5}{*}{ latency } & $\geq 4$ & 293 & -0.06 & 0.34 & 0.04 & 0.45 & 0.07 & 0.26 & 0.00 & 0.98 \\
\hline & $\geq 5$ & 254 & -0.04 & 0.48 & 0.02 & 0.78 & 0.04 & 0.48 & 0.00 & 0.98 \\
\hline & $\geq 6$ & 202 & -0.05 & 0.46 & -0.04 & 0.58 & 0.02 & 0.78 & -0.04 & 0.59 \\
\hline & $\geq 7$ & 121 & -0.03 & 0.78 & -0.07 & 0.42 & -0.01 & 0.87 & -0.06 & 0.48 \\
\hline & $\geq 8$ & 37 & 0.23 & 0.16 & 0.07 & 0.70 & 0.19 & 0.26 & -0.02 & 0.91 \\
\hline \multirow{6}{*}{$\begin{array}{l}\text { Visual search } \\
\text { task, \% of } \\
\text { successful search, } \\
\text { conjunction }\end{array}$} & $\geq 3$ & 340 & 0.11 & 0.05 & 0.01 & 0.84 & 0.08 & 0.15 & 0.14 & 0.01 \\
\hline & $\geq 4$ & 304 & 0.09 & 0.11 & -0.02 & 0.67 & 0.05 & 0.41 & 0.12 & 0.03 \\
\hline & $\geq 5$ & 258 & 0.06 & 0.32 & -0.01 & 0.88 & 0.02 & 0.71 & 0.10 & 0.11 \\
\hline & $\geq 6$ & 203 & 0.06 & 0.40 & 0.01 & 0.86 & 0.05 & 0.45 & 0.16 & 0.02 \\
\hline & $\geq 7$ & 121 & 0.06 & 0.54 & 0.04 & 0.64 & 0.02 & 0.80 & 0.11 & 0.22 \\
\hline & $\geq 8$ & 37 & 0.23 & 0.19 & 0.09 & 0.59 & 0.01 & 0.98 & 0.11 & 0.53 \\
\hline \multirow{6}{*}{$\begin{array}{l}\text { Anticipatory } \\
\text { attention shifts } \\
\text { task, \% of correct } \\
\text { anticipation, post- } \\
\text { switch }\end{array}$} & $\geq 3$ & 365 & 0.03 & 0.55 & -0.05 & 0.33 & 0.07 & 0.17 & 0.04 & 0.41 \\
\hline & $\geq 4$ & 355 & 0.03 & 0.54 & -0.06 & 0.26 & 0.05 & 0.39 & 0.04 & 0.51 \\
\hline & $\geq 5$ & 338 & 0.04 & 0.52 & -0.05 & 0.38 & 0.04 & 0.52 & 0.05 & 0.36 \\
\hline & $\geq 6$ & 330 & 0.03 & 0.54 & -0.05 & 0.35 & 0.04 & 0.49 & 0.03 & 0.60 \\
\hline & $\geq 7$ & 315 & 0.02 & 0.74 & -0.07 & 0.25 & 0.04 & 0.47 & 0.05 & 0.37 \\
\hline & $\geq 8$ & 295 & 0.02 & 0.79 & -0.08 & 0.17 & 0.03 & 0.65 & 0.05 & 0.44 \\
\hline \multirow{6}{*}{$\begin{array}{l}\text { Attention to faces } \\
\text { task, dwell time } \\
\text { index on faces }\end{array}$} & $\geq 3$ & 312 & -0.06 & 0.33 & -0.12 & 0.04 & -0.09 & 0.10 & 0.00 & 0.94 \\
\hline & $\geq 4$ & 272 & -0.04 & 0.50 & -0.16 & 0.01 & -0.14 & 0.03 & 0.03 & 0.65 \\
\hline & $\geq 5$ & 221 & -0.03 & 0.69 & -0.17 & 0.01 & -0.11 & 0.09 & -0.03 & 0.64 \\
\hline & $\geq 6$ & 178 & -0.01 & 0.87 & -0.22 & $<0.01$ & -0.13 & 0.09 & 0.01 & 0.89 \\
\hline & $\geq 7$ & 109 & -0.01 & 0.91 & -0.26 & 0.01 & -0.13 & 0.19 & -0.04 & 0.68 \\
\hline & $\geq 8$ & 39 & 0.06 & 0.74 & -0.28 & 0.09 & 0.00 & 0.99 & -0.25 & 0.13 \\
\hline
\end{tabular}

$\dagger$ Values from Spearman’s rank correlation for visual search latency, Spearman’s partial rank correlation for visual search task (adjusted to one-object and multiple-objects), anticipatory

attention shifts task (adjusted to pre-switch), and dwell time index on faces (adjusted to dwell time index on control stimulus). 